\title{
Entry and Exit in Disequilibrium
}

\author{
Andrew Burke (Cranfield School of Management, UK)* and Andre van Stel (EIM, \\ Netherlands)
}

\begin{abstract}
Most entrepreneurship theory depicts disequilibrium as the most common state for entrepreneurial activity and yet remarkably very little empirical research investigates the role of entry and exit in this type of external environment. Drawing on economics and organizational ecology we outline reasons why the interrelation between entry, exit and incumbent firms is likely to vary when the actual number of firms is higher or lower than the number that a market can sustain. We also introduce a new empirical methodology to explain entry and exit levels in two different types of disequilibria comprising situations when markets under and over shoot carrying capacity. Using a data set on the retail industry, we find that in undershoots a lack of competition between incumbent firms restores equilibrium by creating room for new-firm entry. In contrast, in overshoots competition induced by new firms (in particular strong displacement) restores equilibrium. We also find that equilibrium-restoring mechanisms are faster in over than undershoots. The results highlight that the behaviour and impact of entry and exit varies depending on the type of disequilibrium.
\end{abstract}

Keywords: entry, exit, replacement, displacement, carrying capacity, disequilibrium, undershooting, overshooting

JEL codes: B50, J01, L00, L1, L26 


\section{Introduction}

This paper investigates how the pattern and impact of firm entry and exit changes when markets are more and less crowded. It is motivated by a common theme in economics and organizational ecology which indicates that markets have a limited capacity to sustain firms (Boone and Van Witteloostuijn, 1995, and Geroski, 2001). Put differently, for any given market size and set of technological features, there is a limited number of businesses that any market can support. In the economics literature this point in a market is described as an equilibrium while in organizational ecology it is a steady state referred to as 'carrying capacity' (Hannan and Freeman, 1989). Both schools of thought take the view that markets gravitate towards this point of equilibrium or carrying capacity. This implies that if the actual number of firms has deviated from an equilibrium or carrying capacity that in the long run it will converge to this point. The focus of interest of each school implies that the long run is a shorter time period in economics than in organizational ecology. The economics literature provides a deep compendia of analysis on the determinants of steady state equilibria with only a small proportion of research is devoted to tracking the dynamic process in disequilibrium ${ }^{1}$. By contrast, the organizational ecology literature provides less detail on the different structural forms that the carrying capacity steady state may take and instead examines the adjustment process towards this point of gravitation in the market. The ecological models used in the process manifest a slower evolutionary journey to equilibrium.

The founding fathers of entrepreneurship theory viewed disequilibrium as the most natural state for entrepreneurial activity (Knight, 1921, and Schumpeter, 1934). Remarkably, very little empirical research accounts for the role of disequilibrium when examining entrepreneurial performance at the level of the market. This paper seeks to shed some new light in this area by outlining some relevant theory as well as offering an empirical methodology that can be used to explore the role of market over and undershoots (i.e. situations where the actual number of firms is higher and lower respectively than the equilibrium number). We examine the entry and exit process when the actual number of firms in the market deviates from its carrying capacity. In particular, we are interested in the role of displacement (entry displacing incumbents) and replacement effects (exit attracting entry) when markets over and under shoot their equilibrium or

\footnotetext{
${ }^{1}$ For example, see Tirole (1988) and Martin (2002).
} 
carrying capacity. Besides, we are also interested if and how the extent of disequilibrium in itself affects entry and exit in over and undershoots. We delve into economics and organizational ecology theory and develop testable hypotheses which indicate that replacement and displacement effects will differ in over and undershoots. We also test the core assumption of both schools of thought relating to the existence of an equilibrium or carrying capacity as a point of gravitation in the market as well as investigating the speed of adjustment towards this point in both over and undershoots.

In order to achieve these objectives we offer an easy to adopt empirical methodology. Firstly, we account for the possibility that the adjustment process in an undershoot is not the same as in an overshoot. We estimate an equation for the long-run sustainable number of firms and use this to identify periods of over and undershooting. We then very simply divide the sample into periods of over and undershooting to estimate entry and exit equations separately in each of these regimes. This enables us to see whether the specification of entry and exit equations differs between these two forms of disequilibrium. This method tests if and how each type of disequilibrium affects the interaction between entry and entry (i.e. replacement and displacement effects) differently but it leaves open the issue of whether the scale of disequilibrium also has an influence (e.g. whether a $5 \%$ compared to a $50 \%$ overshoot has the same or a different magnitude of effect). Our second methodological approach tackles this latter question by introducing a revised error-correction model which accounts for the impact of the scale of disequilibrium and importantly decomposes the error-correction effect (i.e. the adjustment back to equilibrium) into unique effects attributable to the disequilibrium number of incumbent firms on the one hand, and the interrelation between entry and exit levels on the other hand. Therefore, we believe that we offer a simple methodological blueprint of how one can unpack the behaviour of entry and exit in the various types and scales of disequilibrium.

We apply this approach to a unique detailed data base on the Dutch retail industry which involves 41 shop types over a twenty-two year period (1980-2001). We develop a dynamic equilibrium function for the number of firms at carrying capacity while introducing an errorcorrection framework. We investigate whether firm entry and exit relationships and the equilibrium-restoring mechanisms differ in situations of 'undershooting' (the actual number of firms is below the equilibrium number) and 'overshooting' (the actual number of firms is above the equilibrium number). The organisation of the paper is as follows. We start with an outline of the 
theory and hypotheses. This is then followed by a section outlining a methodological approach to account for entry and exit in disequilibrium. We also discuss a strategy to apply our methodological approach in an empirical setting. We then discuss the empirical model and the data. In the next section we outline the results and conduct some simulations to illustrate the entry and exit adjustment process towards equilibrium. The final section is left for discussion and conclusions.

\section{Theory and Hypotheses}

\subsection{The role of entrepreneurship in disequilibrium}

The main contribution that the theory of entrepreneurship has made to economics has been to provide an account of what happens in disequilibrium (Knight 1921, Schumpeter, 1934, Von Mises, 1949, Kirzner 1973). This has a long tradition of being ignored in economics which is mainly focused on seamless movement from one equilibrium to another (see Casson, 1982; Parker and Stead, 1991). By contrast economics theorists interested in entrepreneurship portrayed entrepreneurs as activists responsible for creating disequilibrium. Schumpeter (1934) argued that through introducing innovation (new combinations) to a market entrepreneurs create disequilibrium. Von Mises (1949) and Kirzner (1973) argued that entrepreneurs are innovative through 'imagination' and 'alertness to new market opportunities' respectively. Knight (1921) argued that entrepreneurs' key attribute was an ability to deal with a state of flux where levels of uncertainty were high and entrepreneurs' actions involved impure (uninsurable) risk taking. It was not until the work of Schultz $(1975,1980)$ and Casson (1982) that the synergistic elements of both schools of thought became apparent. These latter studies depict entrepreneurs as both the initiators of disequilibrium and then an equilibrating force through their imitative actions (diffusing innovation).

Despite this theoretic account of the role that entrepreneurs play in disequilibrium, remarkably, nearly all empirical analysis of entrepreneurship does so in an equilibrium context - usually, in the form of estimating long-run equilibrium relationships/equations to identify the determinants of firm entry, exit and growth (see Parker, 2004, Shane, 2003, and Minniti and Levesque 2008). Carree and Thurik (1996) and Burke (1996) are exceptions but we will explain in Appendix 1 why these approaches are incomplete; only considering part of the disequilibrium effect and using techniques 
with overly restrictive (unrealistic) economic properties.

The essence of the organizational ecology literature is to focus on adjustment processes towards a point of market gravity. This steady state is defined by the carrying capacity of the market to sustain particular types of firms (Hannan and Freeman, 1989). Below carrying capacity firms thrive as a result of access to an abundance of resources while above it competition for insufficient resources affects firm fitness and increases the exit rate (Hannan and Freeman, 1977). A more sustainable and steady state emerges when the actual number of firms is equal to the carrying capacity (Hannan and Freeman, 1989). As far as the impact of competition on the sustainable number of firms is concerned, the logic behind equilibrium in economics resonates with the logic behind the carrying capacity in organizational ecology (Geroski, 2001). Both Schools identify that markets gravitate towards a sustainable number of firms which is determined by the volume of consumer expenditure and the nature of factor/input markets; particularly their technological features. Therefore, for brevity we will use the single word 'disequilibrium' to refer to states where the actual number of firms deviates from this point of market gravity and hence by definition is in an unsustainable state. The notion that markets have a limited capacity to sustain firms gives rise to a necessary condition for the existence of a market's carrying capacity or equilibrium: In order for a market's carrying capacity to exist, the change in the actual number of firms must be positive below carrying capacity and negative above it.

Two mechanisms may contribute to fulfill this necessary condition, i.e. to restore equilibrium. Firstly, the scale of disequilibrium itself plays a role. As mentioned earlier, when markets under shoot there is an abundance of resources which attracts new firms. At the same time exit rates will be lower as incumbent firms thrive. When markets over shoot, resources are insufficient which increases exit and makes entry less attractive. These observations give rise to hypotheses $1 \mathrm{a}$ and $1 \mathrm{~b}$ :

Hypothesis 1a: In an undershoot, the greater the extent of disequilibrium (i.e. the lower the number of firms), the higher (lower) the number of entries (exits).

Hypothesis 1b: In an overshoot, the greater the extent of disequilibrium (i.e. the higher the number of firms), the lower (higher) the number of entries (exits).

Both hypotheses imply that excessive or deficient numbers of incumbent firms (i.e. the scale of 
disequilibrium) in itself contributes positively to error-correction, i.e. towards a restoration of equilibrium (if they are confirmed).

A second mechanism that may restore equilibrium relates to the interrelation between entry and exit, i.e. replacement and displacement effects. Tight niche packing or crowding (Hannan and Freeman, 1989, Hannan and Carroll, 1992) indicates that entry into high density markets should cause greater exits than entry into less dense markets as there are more firms on the margin of viability whereas in a less competitive market under shooting its carrying capacity, entry may cause a reduction in profits but not to the point of causing exit. Likewise, in high density markets there are less opportunities for new and existing businesses to reposition themselves through strategies such as product differentiation (Hotelling, 1929 and Chamberlin, 1933) and resource partitioning (Carroll, 1985) in order to avoid the negative impact of competition. Furthermore, the fitness of incumbent firms is likely to be lower when the actual number of firms is above market carrying capacity (Hannan and Freeman, 1977 and 1989). Therefore, incumbents are easier to displace in an overshoot than an undershoot. There may also be a selection effect in operation where lower ability potential entrants are more likely to choose to enter in an undershoot than an overshoot as they know that they are less likely to survive a highly competitive high density market. Since more able entrants would be expected to have higher displacement effects than less able entrants it again follows that displacement effects are likely to be stronger in high density market overshoots than in less crowded undershoots. In a similar logical vein one would expect incumbent firms to occupy more market space and to be more fit in a less crowded undershoot than in a high density overshoot. Therefore, the exit of a firm in an undershoot may be expected to create a larger replacement effect (exit freeing up resources and drawing in new entrants - Delacroix and Carroll, 1983) than in an overshoot. Regarding the relative importance of replacement and displacement effects in under and overshoots, the above theory implies the following hypothesis:

\section{Hypothesis 2: In an undershoot (overshoot) replacement effects are stronger (weaker) than displacement effects.}

If confirmed, hypothesis 2 implies that the interrelation between entry and exit contributes positively to error-correction, i.e., to a restoration of equilibrium. In order for the necessary condition of the existence of a market's carrying capacity or equilibrium to be fulfilled, at least one 
of the two hypotheses 1 and 2 must hold true.

\subsection{Speed of adjustment}

A key dividing line between economics and organizational ecology is that the former views firms as more agile than the latter. Arrow ( 1974) and Hannan and Freeman (1977) argue that firms suffer from organizational inertia so that they are slow to adapt to changing market conditions. This organizational inertia can be driven by the practices and routines that businesses adopt (Nelson and Winter, 1982 and Hannan and Freeman 1989) as well as isomorphism - the pressure to conform to an industry standard in order to gain legitimacy (Hawley, 1968). However, market conditions can change and when they do then existing routines and practices may no longer be optimal. Hannan and Freeman (1989) argue this change is difficult and it can sometimes mean losing core competences (Dobrev et al, 2001). It can create political opposition as employees skills/motivations are committed to the status quo of established practices and routines (Dobrev and Barnett, 2001). Furthermore, change reintroduces established business to new practices and hence re-exposes them to the 'liability of newness' (Hannan and Freeman, 1984, Amburgey et al., 1996, and Peli et al 2000). Also organizational change is itself detrimental for survival (Barnett and Carroll, 1995 and Dobrev et al 2001) so even if a firm realises that it will need to change it may try to delay adopting the change until it is absolutely critical.

So if incumbents are going to be slow drivers of the market adjustment process towards carrying capacity then this implies a greater role for entry and exit. However, both schools of thought believe that entry and exit can be slow to function. The industrial economics literature documents the role of fixed and sunk costs as barriers to entry and exit (Sutton, 1991). Likewise the economics of entrepreneurship literature highlights financial and human capital constraints on firm entry (Evans and Jovanovic, 1989 and Burke et al, 2000). The organizational ecology literature indicates that entry may be deterred by the 'liability of newness' (Stinchcombe, 1965) and legitimation effects (Hannan and Freeman, 1989) which cause entrants to be particularly vulnerable to failure.

Combining the organizational inertia of incumbents with the impediments on entry and exit gives rise to hypothesis 3 :

Hypothesis 3: If incumbents suffer from organizational inertia and if the entry and exit processes face significant impediments then the adjustment process towards carrying capacity 
will be slow.

Exit can be an emotionally and financially painful decision to make. Likewise, the factors causing organizational inertia imply that manager and employee stakeholders in incumbent firms are likely to 'hang on to the bitter end' rather than give up and exit when the end is in sight; thereby causing persistence in market overshoots. So when the actual number of firms over shoots the market carrying capacity these forces may slow down the exit rate and in turn the pace of adjustment to equilibrium. By contrast, the decision not to enter entails less emotional and financial costs as at this stage relatively little human and financial resources have been committed to the venture. If there are little resource constraints on entrants then one would imagine that the pace of the adjustment process is faster when the actual number of firms under shoots market carrying capacity than when it over shoots this point of market gravity. However, if the actual number of firms under shooting the market carrying capacity is due to strong barriers to entry and start-up resource constraints (particularly finance) then one would expect the adjustment process to be slower in under than overshoots. These insights give rise to the following hypothesis:

Hypothesis 4: If barriers to exit and organizational inertia are relatively stronger (weaker) constraints on exit than barriers to entry and start-up resource constraints are on entrants then the pace of the adjustment process towards carrying capacity will be faster (slower) in an undershoot than in an overshoot.

We cannot directly test hypothesis 4 but it does imply that empirical analysis cannot assume that the speed of the adjustment process towards carrying capacity or equilibrium is similar in over and undershoots. Therefore, these implications justify our empirical methodology which separately investigates the adjustment processes in over and undershoots. We now move onto the development of an empirical methodology to test the hypotheses developed in Section 2.

\section{Empirical Methodology and Data}

The aim of our paper is to investigate whether excessive or deficient numbers of incumbent firms (i.e. the scale of disequilibrium) in itself form the main equilibrating mechanism, or, alternatively, the interrelation between entry and exit (i.e. replacement and displacement effects). We also ask ourselves the question in this paper whether the relative importance of these two 
mechanisms differs between undershoot and overshoot situations.

In order to address these issues we use the following model set-up. In Appendix 1 we describe how our model set-up extends and refines earlier approaches used in the literature to model the interrelation between entry, exit and the number of firms in an industry.

$$
\begin{aligned}
& \operatorname{NOF}_{t}^{*}=\operatorname{NOF}_{t} *\left(X_{t}\right) \\
& \operatorname{ENTRY}_{t}=\alpha_{0}+\sum_{i=1}^{n} \alpha_{i}\left(w_{i t}-w_{i t-1}\right)+\psi\left(N O F_{t-2}-N O F^{*}{ }_{t-1}\right)+\varphi \operatorname{ENTRY}_{t-1}+\gamma \operatorname{EXIT}_{t-1}+\mu \operatorname{EXIT}_{t} \\
& \operatorname{EXIT}_{t}=\beta_{0}+\sum_{i=1}^{n} \beta_{i}\left(w_{i t}-w_{i t-1}\right)+\theta\left(N O F_{t-2}-N O F_{t-1}^{*}\right)+\rho \operatorname{ENTRY}_{t-1}+\tau \operatorname{EXIT}_{t-1}+\phi \operatorname{ENTRY}_{t}
\end{aligned}
$$

In equation (1) it is assumed that the equilibrium number of firms $N O F_{t} *$ in an industry is a function of factors $X_{t}=\left\{x_{i=1 t}, \ldots, x_{n t}\right\}$ affecting the capacity of an industry to support viable firms. In equations (9) and (10) entry and exit rates depend on three sets of variables. ${ }^{2}$ First, the gap between the actual and equilibrium number of firms, $\left(N O F_{t-2}-N O F_{t-1}^{*}\right)$, is included to measure the scale of disequilibrium. ${ }^{3}$ Second, the lagged and current entry and exit rates are included in order to compute replacement and displacement effects. Finally, there is (a first difference of) a vector of control variables $W$. For the specificities of the set-up (e.g. the variables included in vectors $X$ and $W$ ) we refer the reader to Appendix 1.

The course of the error-correction process is determined by the impact of the scale of disequilibrium regarding the number of incumbent firms (modelled by parameters $\psi$ and $\theta$ ) and by the replacement (exit causing entry) and displacement (entry causing exit) effects. For the definition of the replacement and displacement effects in terms of the model parameters, we refer to equation (11) in Appendix 1.

\subsection{Empirical strategy}

Our empirical application will consist of joint estimation of equations (1), (9) and (10). In the next sections we will present our empirical model for the Dutch retail industry including the

\footnotetext{
${ }^{2}$ Equations (9) and (10) follow from a series of extensions and refinements of earlier approaches used in the literature. These extensions and refinements are described in equations (2)-(8) which are included in Appendix 1.

${ }^{3}$ In the course of one year the number of firms will rarely change greatly, so that the term $\left(N O F_{t-2}-N O F_{t-1}^{*}\right)$ approximately equals $\left(N O F_{t-1}-N O F_{t-1}^{*}\right)$. Therefore, we loosely use the term scale or extent of disequilibrium for both expressions.
} 
organization of the various model variables. However, in the current subsection we will first present our estimation strategy in terms of the theoretical equations derived earlier in this section.

Our first approach to account for disequilibrium in entrepreneurship consists of modelling the interrelation between entry and exit. This approach is capable of accommodating different replacement and displacement effects but without making a distinction between under and overshoot situations, this approach does not feature equilibrium restoring behaviour. Either the replacement effect dominates or the displacement effect so that in the long run the number of firms goes to infinity or to zero. This is not realistic.

Using the entry/exit model, equilibrium-restoring behaviour can be accommodated by allowing the replacement and displacement effects to be different in situations where the number of firms is below or above its long-run sustainable value. In particular, an equilibrium-restoring process is consistent with a dominant replacement effect in case of undershooting and a dominant displacement effect in case of overshooting (see hypothesis 2). Therefore our first aim is to investigate whether we actually find these error-correction characteristics if we estimate the entry/exit model separately for under and overshooting. For this test, we refrain from the second equilibrium restoring process, i.e. we do not include the variable measuring the extent of disequilibrium $\left(\mathrm{NOF}_{t-2}-N O F^{*}{ }_{t-1}\right)$, so that we obtain a 'pure' comparison of the replacement and displacement effects. In other words, we estimate the model formed by equations (1), (9) and (10) but without estimating parameters $\psi$ and $\theta$.

In order to be able to make a distinction between situations of under and overshooting, we will start by estimating the long-run sustainable number of firms (equation 1). Observations for which $N_{O F} F_{t-1}<(>) N O F^{*}{ }_{t-1}$ are characterized by undershooting (overshooting). ${ }^{4}$ Next, as just described, we estimate the model separately for under and overshooting while excluding the $\left(N O F_{t-2}-N O F_{t-1}^{*}\right)$ variable. This will give us some first insights about (a) the equilibriumseeking behaviour of the entry/exit model in under and overshooting, and (b) the ability of the estimated long-run function to empirically distinguish between under and overshooting situations. If the error-correction requirements of the model are met by the estimation results, this would provide some confidence that the entry/exit model is not mis-specified, and, in addition, that the estimation of the long-run number of firms is also not implausible. 
The final step of our regression exercises will be to estimate the full model (including parameters $\psi$ and $\theta$ ), again separately for under and overshooting. This will allow us to investigate whether the extent of disequilibrium adds to the explanation of entry and exit levels, next to the replacement and displacement effects. It will also shed light on the question which mechanism is more important for restoration of equilibrium: the interrelation between entry and exit (replacement and displacement effects) or the autonomous effect of the number of firms being out-of-equilibrium (variable $\left(N O F_{t-2}-N O F_{t-1}^{*}\right)$ ). We can also see whether these mechanisms work out differently for under and overshooting situations. We then conclude the analysis with a series of simulations illustrating how the adjustment process operates in disequilibrium for both over and undershoots.

\subsection{The Model Specification}

Our model consists of an equation describing the long-run sustainable number of firms (equation 1 below), as well as an entry and an exit equation structured in line with equations (9) and (10) in the previous section. Our model reads as follows.

$$
\begin{aligned}
N O F_{i t}= & \gamma_{1 i}+\gamma_{2} \pi_{i t}+\gamma_{3} M I_{t}+\gamma_{4} C S_{i t}+\gamma_{5} T U R_{i t}+\gamma_{6} I R_{t}+\gamma_{7} H P_{t}+v_{i t} \\
N O F_{i t}^{*}= & \hat{\gamma}_{1 i}+\hat{\gamma}_{2} \pi_{i t}+\hat{\gamma}_{3} M I_{t}+\hat{\gamma}_{4} C S_{i t}+\hat{\gamma}_{5} T U R_{i t}+\hat{\gamma}_{6} I R_{t}+\hat{\gamma}_{7} H P_{t} \\
E N T R Y_{i t}= & \alpha_{0 i}+\alpha_{1} P M I_{i t-1}+\alpha_{2} D C S_{i t-1}+\alpha_{3} U N_{t-1}+\alpha_{4} D U N_{t-1}+\alpha_{5} D F_{i t-1}+\alpha_{6} S S P_{i t-1}+\alpha_{7} F S_{i t-1}+ \\
& \alpha_{8} I R_{t}+\alpha_{9} H P_{t}+\alpha_{10} E X I T_{i t}+\alpha_{11} E X I T_{i t-1}+\alpha_{12} E N T R Y_{i t-1}+\alpha_{13}\left(N O F_{i t-2}-N O F_{i t-1}^{*}\right)+\varepsilon_{i t} \\
\operatorname{EXIT}_{i t}= & \beta_{0 i}+\beta_{1} P M I_{i t-1}+\beta_{2} D C S_{i t-1}+\beta_{3} U N_{t}+\beta_{4} D U N_{t}+\beta_{5} D F_{i t}+\beta_{6} S S P_{i t}+\beta_{7} F S_{i t}+ \\
& \beta_{8} I R_{t}+\beta_{9} H P_{t}+\beta_{10} E N T R Y_{i t}+\beta_{11} E X I T_{i t-1}+\beta_{12} E N T R Y_{i t-1}+\beta_{13}\left(N O F_{i t-2}-N O F_{i t-1}^{*}\right)+\eta_{i t}
\end{aligned}
$$

Where:

NOF natural logarithm of the number of firms (end of year)

$N O F^{*} \quad$ natural logarithm of the equilibrium number of firms

$\pi \quad$ natural logarithm of the average profit per store (in 1990 prices)

\footnotetext{
${ }^{4}$ Since we will use OLS, the limit probability that industries are exactly in equilibrium, i.e., that $N O F_{t-1}=N O F^{*}{ }_{t-1}$, is zero.
} 
MI natural logarithm of the average modal income (in 1990 prices)

CS natural logarithm of the total consumer spending (in 1990 prices)

TUR natural logarithm of turbulence (sum of entry and exit)

$I R \quad$ average interest rate of the five types of long term Dutch state loans

$H P \quad$ index of average house price

ENTRY entry rate: number of entries divided by number of firms at start of year

EXIT exit rate: number of exits divided by number of firms at start of year

$P M I \quad$ average profit divided by modal income

DCS (relative) change in real consumer spending

UN number of unemployed (in millions)

DUN (absolute) change of number of unemployed (in millions)

$D F \quad$ degree of franchising: number of franchisees as a fraction of the total number of firms

SSP small store presence: share of small firms (less than ten employees) in total industry turnover

FS floorspace requirement (in 10,000 square meters)

$v \quad$ disturbance term of equation (1)

$\varepsilon, \eta \quad$ disturbance terms of equations (9) and (10), possibly correlated

$\mathrm{i}, \mathrm{t} \quad$ indices for shop type (industry) and year, respectively

A novelty of our model is that it includes a function for the long-run equilibrium sustainable number of firms in an error-correction framework. This equilibrium number of firms (i.e. carrying capacity) in an industry is related to factors influencing firm viability such as elements of the revenues and costs of the entrepreneur, demand, entry and exit barriers, and liquidity. ${ }^{5}$ The aim is to investigate whether or not there is an autonomous effect on entry and exit if the number of firms in an industry is in disequilibrium. In other words, if the number of firms is lower than may be expected on the basis of some key determinants of the long-run number of firms, this may indicate incentives to entry (e.g. competition may be relatively low which may make it easier for an entrant to make profits) and disincentives to exit (low competition makes it easier to survive). Analogously, a situation where the number of firms is relatively high may make it less attractive to enter and may cause exit levels to be higher (as competition between incumbents may be higher). Hence, parameters $\alpha_{13}$ and $\beta_{13}$ are expected to be negative and positive, respectively. These expected parameter values relate to hypotheses $1 \mathrm{a}$ and $1 \mathrm{~b}$, developed in Section 2.1.

The equilibrium equation (1b) is defined in log-levels (as we explain the absolute number of firms, not a ratio) and we include the self-employment income (i.e. net profit), the opportunity costs

\footnotetext{
${ }^{5}$ Following usual convention in error correction modelling (in particular vector error correction models with cointegration, see Heij et al., 2004, Section 7.6.3), we assume that the relation between the variables in the long-run equilibrium is of a non-causal nature.
} 
of self-employment (i.e. modal income), the demand for products and services sold in the shop type and the level of turbulence, which is a measure of entry and exit barriers. In addition, we include the interest rate and the average house price which are indicators for the cost of capital and cost of property, respectively. See equation (1b).

The effect of profits (parameter $\gamma_{2}$ ) is indeterminate from theory. Higher profits will attract more firms but once more firms enter the market (in particular imitative entries), average profits will drop. Hence, in the long run the relation could be either positive or negative (Burke, van Stel and Thurik, 2010). A higher modal income reflects higher opportunity costs of entrepreneurship hence $\gamma_{3}$ is expected to be negative. Higher demand creates room for more firms ( $\gamma_{4}$ positive), and higher turbulence indicates lower barriers which is associated with room for more firms in the market ( $\gamma_{5}$ positive). If the costs of attracting loans or the costs of renting floor space increase over time, less people may be inclined to start businesses: $\gamma_{6}$ and $\gamma_{7}$ are expected to be negative. In addition, we include industry-specific constants $\gamma_{1 i}$ (i.e. fixed effects). These dummy variables capture structural differences between industries such as the minimum efficient scale, capital requirements, market size, and so on.

Equations (9) and (10) contain several determinants of entry and exit. As profits are a good reflection of the income of entrepreneurs in the retail industry (the vast majority runs unincorporated businesses) we use the profits to modal income ratio (PMI) to measure the relative attractiveness to enter a shop type. Demand growth is measured by the growth rate of consumer expenditures on the goods and services sold in the shop type (DCS). While the variables PMI and DCS are expected to have a positive impact on entry, they are expected to have a negative impact on exit at the same time. Unemployment (UN) and change in unemployment (DUN) may have a positive effect on entry as the (newly) unemployed may have limited alternative employment options in the wage sector. High unemployment is also a disincentive to exit as economic circumstances are not favourable to find a different occupation. Alternatively, one may hypothesise that high unemployment rates indicate unfavourable market conditions to start or maintain a business, consistent with opposite expected effects on entry and exit (Thurik et al., 2008). Following Carree and Thurik (1996), three indicators of entry and exit barriers are included. The degree of franchising (DF) may have a negative impact on entry and a positive impact on exit because franchisees enjoy certain benefits associated with the membership of a franchise chain. 
This may make it more difficult for independent new firms to enter or, when entered, to survive. Small store presence (SSP) is a general indicator of (low) entry and exit barriers. In industries with a high output share of small firms, economies of scale are apparently not so important, and entry and exit may occur more often. Hence the expected sign is positive on both entry and exit. The variable 'floorspace requirements' (FS) is an indicator of required investments. When a large shop is needed to run a business, more capital is required which may be difficult to obtain. Also, once entered, often large investments are made which makes the entrepreneur less flexible to exit the shop type. Hence the expected effect is negative, both for entry and exit. In addition, fluctuations in interest rates and house prices (variables IR and HP) are expected to influence not only the long-run sustainable number of firms (see equation (1b)) but also short-run market dynamics. Finally, industry fixed effects are included to capture structural differences in market dynamics between different industries. Note that all variables are entered with a lag except for the unemployment and barrier variables for the exit equations, which are assumed to have an immediate impact. ${ }^{6}$

Replacement and displacement effects are measured in line with the definitions in equation (11) in Appendix 1. Hence, the replacement effect can be computed as $\frac{\alpha_{10}+\alpha_{11}}{1-\alpha_{12}}$. Analogously, from equation (10) the displacement effect can be computed as $\frac{\beta_{10}+\beta_{12}}{1-\beta_{11}}$. As explained in the previous section these can be estimated separately for under and overshoot sample splits. These replacement and displacement effects relate to hypothesis 2, developed in Section 2.1.

\subsection{The Data}

We use a data base for 41 shop types (i.e., industries at approximately fourth digit level) within the retail sector over the period 1980-2001. Our data base combines variables from two major sources: the Dutch Central Registration Office (CRK) and a panel of independent Dutch retailers (establishments) called 'Bedrijfssignaleringssysteem' (interfirm comparison system) which was operated by EIM Business and Policy Research in Zoetermeer. The data are complemented and enriched using information from several sources. As the number of shop types investigated in the

\footnotetext{
${ }^{6}$ Variables IR and HP are also entered without a lag, as the unlagged variables turned out to be statistically more strongly related to entry and exit than the lagged variables.
} 
'Bedrijfssignaleringssysteem' has varied in the 1980s and 1990s, our data base is an unbalanced panel. By and large, we have 28 shop types with data for the 1980s and 1990s and 13 shop types with data for the 1990s only. The exact data period per shop type for which entry and exit rates are available is given in Table 1. The table also contains shop type averages for the entry and exit rates. Details on the measurement and source for each variable are given below.

Raw data on the number of firms (NOF) and the numbers of entries and exits are obtained from the Dutch Central Registration Office (CRK). CRK provides data on the number of new registrations and deregistrations of establishments for each shop type. The number of new registrations (deregistrations) divided by the number of firms (at start of year) equals the entry (exit) rate (variables ENTRY and EXIT), while the (logarithm of the) sum of new registrations and deregistrations equals TUR. Over time the sectoral classification of shop types used by CRK changed several times and we corrected for trend breaks that were introduced by these changes (details of these corrections are provided on request from the authors).

Raw data on average (net) profit per store are taken from the 'Bedrijfssignaleringssysteem' (BSS). This panel was started by EIM in the 1970s and each year a large number of firms were asked for their financial performance. We use shop type averages where each shop type average is based on information from about seventy individual retail stores. In addition, for recent years we are also able to check shop type averages using information from Statistics Netherlands. It turned out that differences between these two sources were small which increases confidence in our time series. In our model the average profit level per store is used both in levels (variable $\pi$ ) and relative to modal income (i.e. it is also used as the nominator of the PMI variable). Variable FS (floorspace requirements) is also taken from the 'Bedrijfssignaleringssysteem'.

Data on total consumer spendings on the products and services sold in a certain shop type $C S$ is taken from Statistics Netherlands (publication 'Budgetonderzoeken' or Budget statistics). ${ }^{7}$ The variables modal income $M I$, small store presence $S S P$, and unemployment $U N$ are also taken from Statistics Netherlands. Modal income is also used as denominator of the PMI variable. Data on the degree of franchising $D F$ have been obtained from the Netherlands Central Board for the Retail Trade (HBD), while the interest rate variable $I R$ and the home price index $H P$ are taken from ORTEC, a distinguished financial research firm based in the Netherlands. Finally, for the

\footnotetext{
${ }^{7}$ Total consumer spending was computed by multiplying the variables average household spending, the total number of households
} 
variables profits, modal income and consumer spendings we used a consumer price index to correct for inflation.

in the Netherlands and the share of a certain shop type in total household spendings. 
Table 1: Entry and exit rates for shop types

\begin{tabular}{|c|c|c|c|c|}
\hline Shop type & Period & Average entry rate & Average exit rate & $\mathrm{N}$ \\
\hline Grocers/supermarkets & $1980-2001$ & 0.086 & 0.107 & 22 \\
\hline Greengrocers & $1980-2001$ & 0.083 & 0.110 & 22 \\
\hline Liquor stores & $1980-2001$ & 0.082 & 0.103 & 22 \\
\hline Shoe stores & $1980-2001$ & 0.077 & 0.086 & 22 \\
\hline Furnishing + furniture (mixed) & $1980-2001$ & 0.070 & 0.088 & 22 \\
\hline Bicycle stores & $1980-2001$ & 0.047 & 0.060 & 22 \\
\hline Jewelleries & $1980-2001$ & 0.088 & 0.084 & 22 \\
\hline Drug stores & $1980-2001$ & 0.086 & 0.082 & 22 \\
\hline Florists & $1980-2001$ & 0.115 & 0.116 & 22 \\
\hline Butchers & $1980-2001$ & 0.078 & 0.106 & 22 \\
\hline Fish shops & $1980-2001$ & 0.111 & 0.111 & 22 \\
\hline Bakers & $1980-2001$ & 0.076 & 0.093 & 22 \\
\hline Confectioners & $1980-2001$ & 0.104 & 0.116 & 22 \\
\hline Tobacco shops & $1980-2001$ & 0.050 & 0.086 & 22 \\
\hline Households goods shops & $1980-2001$ & 0.090 & 0.097 & 22 \\
\hline Paint, glass, wall-paper & $1980-2001$ & 0.058 & 0.085 & 22 \\
\hline Hardware stores & $1980-2001$ & 0.066 & 0.084 & 22 \\
\hline Photographer's shops & $1980-2001$ & 0.082 & 0.084 & 22 \\
\hline Pet shops & $1980-2001$ & 0.104 & 0.101 & 22 \\
\hline Textiles mens wear & $1989-2001$ & 0.045 & 0.097 & 13 \\
\hline Furniture & $1980-2001$ & 0.129 & 0.115 & 22 \\
\hline Dairy shops & $1980-2001$ & 0.045 & 0.096 & 22 \\
\hline Electrics & $1980-2001$ & 0.071 & 0.090 & 22 \\
\hline Audiovisual devices & $1980-2001$ & 0.141 & 0.135 & 22 \\
\hline Sewing-machines & $1980-2001$ & 0.065 & 0.095 & 22 \\
\hline Glass, porceline and pottery & $1980-2001$ & 0.129 & 0.121 & 22 \\
\hline Office and school materials & $1980-2001$ & 0.099 & 0.099 & 22 \\
\hline Opticians & $1980-2001$ & 0.098 & 0.072 & 22 \\
\hline Toys & $1980-2001$ & 0.155 & 0.119 & 22 \\
\hline Poultry & $1989-2001$ & 0.069 & 0.105 & 13 \\
\hline Clothing materials & $1989-2001$ & 0.056 & 0.111 & 13 \\
\hline Musical instruments & 1989-2001 & 0.093 & 0.085 & 13 \\
\hline Do-it-yourself shop & $1989-2001$ & 0.129 & 0.105 & 13 \\
\hline Videotheques & $1989-2001$ & 0.328 & 0.309 & 13 \\
\hline Gardening centres & $1989-2001$ & 0.160 & 0.095 & 13 \\
\hline Reform & $1989-2001$ & 0.215 & 0.144 & 13 \\
\hline Baby's clothing & $1989-2001$ & 0.156 & 0.163 & 13 \\
\hline Children's clothing & $1989-2001$ & 0.272 & 0.193 & 13 \\
\hline Textiles underwear & $1989-2001$ & 0.203 & 0.138 & 13 \\
\hline Leather goods & $1989-2001$ & 0.112 & 0.115 & 13 \\
\hline Sport and camping equipment & $1990-2001$ & 0.151 & 0.113 & 12 \\
\hline
\end{tabular}

Note: The second column contains the period for which the entry and exit rates are available. The third and fourth column contain the entry and exit rates, averaged over the period indicated in the second column. The final column contains the number of observations on which the shop type averages in columns 3 and 4 are based.

Source: Dutch Central Registration Office (CRK) and EIM Business and Policy Research. 


\section{Results and Simulations}

As the error terms of equations (9) and (10) are correlated, we estimate the entry and exit equations using three stage least squares (3SLS). ${ }^{8}$ In addition, equation (1) is estimated using OLS and the fitted (i.e. predicted) values of this estimation serve as $N O F{ }_{t}$. This allows us to compute variable $\left(N O F_{t-2}-N O F *_{t-1}\right)$ which is then subsequently inserted into equations (9) and (10). Furthermore, we make a correction for heteroscedasticity caused by the different shop types.

As described earlier, our estimation strategy consists of first estimating equations (1)-(9)-(10) without the error-correction mechanism of the incumbent firms (i.e. excluding variable $N O F_{t-2^{-}}$ $N O F_{t-1}^{*}$ ), to see whether the entry/exit interrelation mechanism shows equilibrium-restoring behaviour (in line with the necessary condition developed in Section 2.1), and then adding the $N O F_{t-2}-N O F_{t-1}^{*}$ variable to see whether the scale of disequilibrium further adds to the explanation of entry and exit levels. The models are estimated separately for under and overshooting.

\subsection{Results for equilibrium number of firms}

After removing seven observations where non-negligible changes in sector classification occur, we have an unbalanced panel of 568 observations distributed over 41 shop types. Estimation results for the long-run sustainable number of firms are presented in Table 2. The coefficients for modal income (negative), consumer spending (positive) and turbulence (positive) are highly significant and in the hypothesised direction. The coefficient for profits is not significant, perhaps indicating that the positive effect of higher profits attracting more firms is neutralised by the negative effect of imitative entry lowering the average profit level in the industry (Burke, van Stel and Thurik, 2010). We find a significant negative coefficient for the house price index, which we use as a rough indicator for the cost of renting floor space. We do not find a significant influence of the interest rate.

\footnotetext{
${ }^{8}$ In equations (9) and (10), the unlagged entry and exit rates on the right-hand-side are the endogenous regressors in the system. We use all other explanatory (exogenous) variables included in equations (9) and (10) as instruments. Since five explanatory variables (UN, DUN, DF, SSP and FS) are included with a lag in the entry equation but without a lag in the exit equation, the model is identified. We deliberately choose as instruments exogenous variables that appear in the other equation of the model. Exogenous variables from other equations in the model are natural candidates to be an instrumental variable because they are correlated with the endogenous regressors via the reduced-form equations, but they are not correlated with the error terms.
} 
Table 2: Estimation results long term relation log of number of firms $(\mathrm{N}=568)$

\begin{tabular}{l|c}
\hline & Long term relation, dependent variable NOF \\
\hline$\pi$ & -0.0068 \\
& $(0.037)$ \\
& $-1.46 * * *$ \\
$C S$ & $(0.30)$ \\
& $0.183 * * *$ \\
$T U R$ & $(0.058)$ \\
& $0.491 * * *$ \\
$I R$ & $(0.026)$ \\
& 0.549 \\
$H P$ & $(0.888)$ \\
& $-0.00058 *$ \\
& $(0.00030)$ \\
$\mathrm{R}^{2}$ & \\
\hline Note: The long term relation is estimated from an OLS regression. Heteroskedasticity-consistent standard errors are \\
between brackets. Dependent variable is the log of the number of firms. Industry fixed effects are included but not \\
reported. \\
$*$ significant at 0.10 level \\
$* *$ significant at 0.05 level \\
$* * *$ significant at 0.01 level
\end{tabular}

The entry and exit equations are estimated separately for under and overshooting. We investigate these by splitting the original sample of 568 observations into a subsample for which the actual number of firms is lower than the estimated equilibrium number of firms (undershooting) and a subsample for which the actual number of firms is higher than the estimated equilibrium number of firms (overshooting).

Before presenting the results for the entry and exit equations, in Table 3 we will first provide some key descriptive statistics for the undershooting and overshooting subsamples. We see that for undershooting, entry and exit rates are higher compared to overshooting. This is probably due to the relatively low number of firms in a situation of undershooting, providing opportunities for new firms to capture a share of the market. Possibly, a substantial part of the new firms fail so that exit rates are also higher in undershooting compared to overshooting. Regarding the deviation between the actual and the equilibrium number of firms, this difference is -almost by construction- bigger for an overshoot situation. In the next subsections we will investigate whether the interrelation between the three variables in Table 3 differs in situations of under and overshooting. 
Table 3: Descriptive statistics for key variables for under and overshooting subsamples

\begin{tabular}{l|ccc}
\hline & Complete sample & Undershooting & Overshooting \\
\hline $\begin{array}{l}\text { Entry rate } \\
\text { Mean } \\
\text { (Standard deviation) }\end{array}$ & 0.100 & 0.114 & 0.084 \\
& $(0.061)$ & $(0.068)$ & $(0.046)$ \\
$\begin{array}{l}\text { Exit rate } \\
\text { Mean }\end{array}$ & 0.107 & & \\
$\quad$ Standard deviation) & $(0.043)$ & 0.116 & 0.096 \\
& & $(0.046)$ & $(0.036)$ \\
NOF $F_{t-2}$ NOF $_{t-1}$ & 0.013 & & 0.143 \\
$\quad \begin{array}{l}\text { Mean } \\
\text { (Standard deviation) }\end{array}$ & $(0.200)$ & -0.100 & $(0.147)$ \\
\hline Number of observations & 568 & $(0.168)$ & 263 \\
\hline
\end{tabular}

\subsection{Results excluding the $N O F_{t-2}-N O F^{*}{ }_{t-1}$ variable}

Results for the entry and exit equations, excluding the $\left(N O F_{t-2}-N O F *_{t-1}\right)$ variable, are in Table 4. We see that there is a positive effect of profits (PMI) on entry and a negative impact on exit. Higher financial returns to running a business are an incentive to enter and a disincentive to exit. The result is stronger for undershooting, possibly indicating that higher profits are even more attractive when there are relatively few competitors in the market. Changes in consumer spending have no impact on entry and exit rates, perhaps indicating that fluctuations in demand are captured by expansion and contraction of incumbent firms. Concerning unemployment, for undershooting we find that a high level of unemployment (variable UN) is related to lower entry and higher exit rates, indicating unfavourable market conditions to start or maintain a business. On the other hand, a high increase in unemployment (variable DUN) is related to higher entry rates, possibly indicating that primarily the newly unemployed are inclined to set up shop while those who are already unemployed for a longer spell are discouraged to employ new initiatives. Results for overshooting are less clear-cut. For the barrier variables DF, SSP and FS, we do not find significant results on entry and exit. Interest rates and house prices (variables IR and HP), indicating the costs of attracting loans and the costs of renting floor space, respectively, are strongly negatively (positively) related to entry (exit), in line with our hypotheses.

Concerning interrelations between entry and exit, we see that replacement is stronger than 
displacement for undershooting, whereas displacement is the dominant market process in case of overshooting. These results are consistent with a mechanism of error-correction: for undershooting replacement dominates, ceteris paribus leading to an increase of the number of firms, while for overshooting the stronger displacement effect leads to a decrease of the number of firms. In both cases the number of firms thus moves in the direction of the long-run sustainable number of firms, thereby meeting the necessary condition formulated in Section 2.1. As equilibrium-seeking behaviour is a standard characteristic of an economic model, these results provide confidence in the specification of our model, formed by equations (1), (9) and(10). In the next subsection we will present the results when the error-correction mechanism for incumbent firms (variable $\left(N O F_{t-2^{-}}\right.$ $\left.N O F^{*}{ }_{t-1}\right)$ is modelled as well. 
Table 4: Estimation results, under and overshooting, excluding error-correction mechanism for incumbent firms

\begin{tabular}{|c|c|c|c|c|}
\hline & \multicolumn{2}{|c|}{ Undershooting $(\mathrm{N}=305)$} & \multicolumn{2}{|c|}{ Overshooting $(\mathrm{N}=263)$} \\
\hline & ENTRY & EXIT & ENTRY & EXIT \\
\hline $\mathrm{PMI}_{\mathrm{t}-1}$ & $\begin{array}{c}0.016 * * * \\
(0.006)\end{array}$ & $\begin{array}{c}-0.011 * * * \\
(0.003)\end{array}$ & $\begin{array}{c}0.010 * * * \\
(0.003)\end{array}$ & $\begin{array}{c}-0.011 * * * \\
(0.003)\end{array}$ \\
\hline $\mathrm{DCS}_{\mathrm{t}-1}$ & $\begin{array}{c}0.009 \\
(0.018)\end{array}$ & $\begin{array}{c}-0.007 \\
(0.010)\end{array}$ & $\begin{array}{l}0.0001 \\
(0.009)\end{array}$ & $\begin{array}{c}0.0008 \\
(0.0099)\end{array}$ \\
\hline $\mathrm{UN}_{(\mathrm{t}-1)}$ & $\begin{array}{c}-0.130 * * * \\
(0.024)\end{array}$ & $\begin{array}{c}0.052 * * * \\
(0.013)\end{array}$ & $\begin{array}{l}-0.020 \\
(0.013)\end{array}$ & $\begin{array}{c}0.016 \\
(0.014)\end{array}$ \\
\hline $\operatorname{DUN}_{(\mathrm{t}-1)}$ & $\begin{array}{c}0.045 * * \\
(0.019)\end{array}$ & $\begin{array}{c}-0.084 * * * \\
(0.019)\end{array}$ & $\begin{array}{c}0.005 \\
(0.007)\end{array}$ & $\begin{array}{c}-0.023 * \\
(0.014)\end{array}$ \\
\hline $\mathrm{DF}_{(\mathrm{t}-1)}$ & $\begin{array}{c}0.005 \\
(0.023)\end{array}$ & $\begin{array}{c}-0.007 \\
(0.013)\end{array}$ & $\begin{array}{l}-0.005 \\
(0.015)\end{array}$ & $\begin{array}{c}0.007 \\
(0.015)\end{array}$ \\
\hline $\operatorname{SSP}_{(\mathrm{t}-1)}$ & $\begin{array}{l}-0.016 \\
(0.031)\end{array}$ & $\begin{array}{c}0.001 \\
(0.015)\end{array}$ & $\begin{array}{l}-0.015 \\
(0.013)\end{array}$ & $\begin{array}{c}0.020 \\
(0.016)\end{array}$ \\
\hline $\mathrm{FS}_{(\mathrm{t}-1)}$ & $\begin{array}{c}0.078 \\
(0.335)\end{array}$ & $\begin{array}{c}0.034 \\
(0.137)\end{array}$ & $\begin{array}{c}0.055 \\
(0.119)\end{array}$ & $\begin{array}{l}-0.017 \\
(0.052)\end{array}$ \\
\hline IR & $\begin{array}{c}-0.725 * * * \\
(0.184)\end{array}$ & $\begin{array}{c}0.389 * * * \\
(0.097)\end{array}$ & $\begin{array}{c}-0.278 * * \\
(0.110)\end{array}$ & $\begin{array}{c}0.293 * * \\
(0.117)\end{array}$ \\
\hline $\mathrm{HP}$ & $\begin{array}{c}-0.00056 * * * \\
(0.00008)\end{array}$ & $\begin{array}{c}0.00030 * * * \\
(0.00004)\end{array}$ & $\begin{array}{c}-0.00023 * * * \\
(0.00005)\end{array}$ & $\begin{array}{c}0.00024 * * * \\
(0.00005)\end{array}$ \\
\hline EXIT & $\begin{array}{c}1.577 * * * \\
(0.312)\end{array}$ & & $\begin{array}{l}0.913 * * * \\
(0.072)\end{array}$ & \\
\hline ENTRY & & $\begin{array}{c}0.554 * * * \\
(0.062)\end{array}$ & & $\begin{array}{c}1.087 * * * \\
(0.083)\end{array}$ \\
\hline $\mathrm{EXIT}_{\mathrm{t}-1}$ & $\begin{array}{c}-0.190 * \\
(0.104)\end{array}$ & $\begin{array}{l}0.107 * \\
(0.056)\end{array}$ & $\begin{array}{c}-0.204 * * * \\
(0.058)\end{array}$ & $\begin{array}{c}0.222 * * * \\
(0.063)\end{array}$ \\
\hline ENTRY $_{\mathrm{t}-1}$ & $\begin{array}{c}0.097 \\
(0.089) \\
\end{array}$ & $\begin{array}{l}-0.034 \\
(0.046) \\
\end{array}$ & $\begin{array}{c}0.227 * * * \\
(0.046)\end{array}$ & $\begin{array}{c}-0.238 * * * \\
(0.053)\end{array}$ \\
\hline Replacement effect & $\begin{array}{c}1.535 * * * \\
(0.280)\end{array}$ & & $\begin{array}{c}0.917 * * * \\
(0.098)\end{array}$ & \\
\hline Displacement effect & & $\begin{array}{c}0.583 * * * \\
(0.068)\end{array}$ & & $\begin{array}{c}1.091 * * * \\
(0.112)\end{array}$ \\
\hline $\mathrm{R}^{2}$ & 0.684 & 0.795 & 0.815 & 0.763 \\
\hline
\end{tabular}

Note: Results are from 3SLS regressions. Heteroskedasticity-consistent standard errors are between brackets. Both the entry and exit equations include industry fixed effects dummies (not reported). NOF* is the predicted value of (the log of) the number of firms, computed from the estimated long term relation reported in Table 2 . The undershooting sample includes those observations for which $\mathrm{NOF}_{\mathrm{t}-1}<\mathrm{NOF}^{*}{ }_{\mathrm{t}-1}$. The overshooting sample includes those observations for which $\mathrm{NOF}_{\mathrm{t}-1}>\mathrm{NOF}_{\mathrm{t}-1}$. The variables UN, DUN, DF, SSP and FS are one period lagged only for the entry equation. The replacement (displacement) effect is computed by summing the coefficients for current and lagged exit (entry), and dividing this sum by one minus the coefficient for lagged entry (exit). Coefficients for lagged endogenous variables are in italics.

* significant at 0.10 level; ** significant at 0.05 level; *** significant at 0.01 level 


\subsection{Results including the $N O F_{t-2}-N O F^{*}{ }_{t-1}$ variable (complete model)}

We now move on to the results when the variable $N O F_{t-2}-N O F_{t-1}^{*}$ is included in the model. See Table 5. Results for profits, change in consumer spending, (change in) unemployment, the degree of franchising, small store presence, floorspace requirements, interest rate and house price are qualitatively similar to those in Table 4.

We focus on the equilibrium-seeking characteristics of the model. Results in Table 5 reveal that error-correction takes place through different mechanisms. For undershooting, we see that displacement is stronger than replacement; although the difference between the two effects is not statistically significant. Still, the replacement and displacement effects do not contribute to errorcorrection, and so hypothesis 2 as it relates to undershoots is not confirmed. Instead, the autonomous effect of the variable $N O F_{t-2}-N O F_{t-1}^{*}$ plays a more important role in restoring equilibrium. The extent of disequilibrium contributes positively to entry ${ }^{9}$ and negatively to exit, supporting hypothesis 1a. The coefficients for undershooting imply that, when at a certain point in time the number of firms is below equilibrium by a certain magnitude, then in the subsequent year $5.2 \%$ of the gap is reduced autonomously by means of a higher number of entries and $4.2 \%$ by means of a lower number of exits. When there are relatively few firms in the market, entrepreneurs identify increased opportunities to make a profit and start new businesses. Also, less firms exit.

For overshooting these effects are $1.0 \%$ (less entries) ${ }^{10}$ and $1.2 \%$ (more exits) of a certain gap between the actual and the equilibrium number of firms. However, these effects are not statistically significant, thereby providing weak support at best for hypothesis $1 \mathrm{~b}$, and error-correction is in fact mainly achieved by the interaction between entry and exit. In particular, displacement is stronger than replacement, implying a tendency for the number of firms to decline (new entries cause relatively many exits while exiting firms are replaced by new firms to a lesser extent). This interplay between entry and exit is in fact by far the dominant equilibrium-restoring mechanism in case of overshooting, as we will illustrate in the next subsection. We conclude that hypothesis 2 as it relates to overshoots is supported. ${ }^{11}$

\footnotetext{
${ }^{9}$ Note that the variable (NOF - NOF*) is negative in case of undershooting, hence the negative coefficient implies more entries.

${ }^{10}$ Note that the variable (NOF - NOF*) is positive in case of overshooting, hence the negative coefficient now implies less entries.

${ }^{11}$ Nevertheless, some caution is required when interpreting these results, as the difference between the displacement and replacement effect is not statistically significant. This is mainly due to the higher standard errors (relative to the coefficients) of the lagged entry and exit rate coefficients. When comparing the difference between the coefficients of the current exit and entry rates (i.e., 0.840-1.179), which constitute the main part of the total displacement and replacement effects, the difference is
} 
In sum, the results indicate that the main driver of equilibrium in an undershoot is that low market density attracts new entrants and enhances firm survival. In other words, a less crowded market offers more market opportunities and less competition for firms thereby providing a stimulus to entrants/entrepreneurs. It is interesting that in an overshoot the effects are not reversed so that high market density and competition don't bring about equilibrium by deterring entry. Instead, this high density market environment tends to give rise to weak (unfit, Hannan and Freeman, 1989) firms who are perceived by entrants to be easy targets for displacement. Entrepreneurs drive the market towards equilibrium by displacing incumbents at a much higher rate than they can do in an undershoot.

As a robustness test, we also estimated the model when using a balanced panel. As can be seen from Table 1, for 13 out of 41 shop types (i.e., one third), the number of years for which data are available is considerably lower than for the other shop types. Hence, our data set is an unbalanced panel. Since consistent estimation of the long-run equilibrium and adjustment relations is facilitated by the availability of data for a long range of years for each shop type, the shorter time period for one third of our shop types could potentially disturb our estimates. Therefore we have also estimated the model when removing these 13 shop types for which the data period is relatively short. We then effectively estimate the model using a balanced panel for 28 shop types. These results are presented in Appendix 2. It is concluded that results are robust for removing the 13 shop types from the data sample.

significant at $10 \%$ level (using a one-tailed test). 
Table 5: Estimation results, under and overshooting, including error-correction mechanism for incumbent firms

\begin{tabular}{|c|c|c|c|c|}
\hline & \multicolumn{2}{|c|}{ Undershooting $(\mathrm{N}=305)$} & \multicolumn{2}{|c|}{ Overshooting $(\mathrm{N}=263)$} \\
\hline & ENTRY & EXIT & ENTRY & EXIT \\
\hline $\mathrm{PMI}_{\mathrm{t}-1}$ & $\begin{array}{c}0.013 * * * \\
(0.004)\end{array}$ & $\begin{array}{c}-0.016 * * * \\
(0.005)\end{array}$ & $\begin{array}{c}0.009 * * * \\
(0.003)\end{array}$ & $\begin{array}{c}-0.010 * * * \\
(0.0036)\end{array}$ \\
\hline $\mathrm{DCS}_{\mathrm{t}-1}$ & $\begin{array}{c}0.010 \\
(0.012)\end{array}$ & $\begin{array}{c}-0.012 \\
(0.011)\end{array}$ & $\begin{array}{r}-0.0002 \\
(0.009)\end{array}$ & $\begin{array}{c}0.001 \\
(0.010)\end{array}$ \\
\hline $\mathrm{UN}_{(\mathrm{t}-1)}$ & $\begin{array}{c}-0.122 * * * \\
(0.017)\end{array}$ & $\begin{array}{c}0.073 * * * \\
(0.027)\end{array}$ & $\begin{array}{c}-0.025 * \\
(0.013)\end{array}$ & $\begin{array}{c}0.023 \\
(0.017)\end{array}$ \\
\hline $\operatorname{DUN}_{(\mathrm{t}-1)}$ & $\begin{array}{c}0.051 * * * \\
(0.018)\end{array}$ & $\begin{array}{c}-0.141 * * * \\
(0.047)\end{array}$ & $\begin{array}{c}0.007 \\
(0.008)\end{array}$ & $\begin{array}{c}-0.030 * \\
(0.018)\end{array}$ \\
\hline $\mathrm{DF}_{(\mathrm{t}-1)}$ & $\begin{array}{c}-0.005 \\
(0.023)\end{array}$ & $\begin{array}{l}0.0003 \\
(0.034)\end{array}$ & $\begin{array}{l}-0.006 \\
(0.014)\end{array}$ & $\begin{array}{c}0.009 \\
(0.016)\end{array}$ \\
\hline $\operatorname{SSP}_{(\mathrm{t}-1)}$ & $\begin{array}{c}-0.037 \\
(0.028)\end{array}$ & $\begin{array}{c}0.015 \\
(0.028)\end{array}$ & $\begin{array}{l}-0.015 \\
(0.013)\end{array}$ & $\begin{array}{c}0.019 \\
(0.020)\end{array}$ \\
\hline $\mathrm{FS}_{(\mathrm{t}-1)}$ & $\begin{array}{c}0.126 \\
(0.357)\end{array}$ & $\begin{array}{c}0.051 \\
(0.215)\end{array}$ & $\begin{array}{c}0.088 \\
(0.155)\end{array}$ & $\begin{array}{l}-0.029 \\
(0.064)\end{array}$ \\
\hline IR & $\begin{array}{c}-0.586 * * * \\
(0.130)\end{array}$ & $\begin{array}{c}0.525 * * * \\
(0.144)\end{array}$ & $\begin{array}{c}-0.285 * * * \\
(0.105)\end{array}$ & $\begin{array}{c}0.317 * * \\
(0.126)\end{array}$ \\
\hline $\mathrm{HP}$ & $\begin{array}{c}-0.00043 * * * \\
(0.00006)\end{array}$ & $\begin{array}{c}0.00039 * * * \\
(0.00009)\end{array}$ & $\begin{array}{c}-0.00022 * * * \\
(0.00004)\end{array}$ & $\begin{array}{c}0.00025 * * * \\
(0.00005)\end{array}$ \\
\hline EXIT & $\begin{array}{c}0.687 * * \\
(0.285)\end{array}$ & & $\begin{array}{c}0.840 * * * \\
(0.105)\end{array}$ & \\
\hline ENTRY & & $\begin{array}{c}0.921 * * * \\
(0.283)\end{array}$ & & $\begin{array}{c}1.179 * * * \\
(0.154)\end{array}$ \\
\hline $\mathrm{EXIT}_{\mathrm{t}-1}$ & $\begin{array}{l}-0.069 \\
(0.072)\end{array}$ & $\begin{array}{c}0.076 \\
(0.061)\end{array}$ & $\begin{array}{c}-0.176 * * * \\
(0.057)\end{array}$ & $\begin{array}{c}0.212 * * * \\
(0.067)\end{array}$ \\
\hline ENTRY $_{\mathrm{t}-1}$ & $\begin{array}{c}0.152 * * \\
(0.065)\end{array}$ & $\begin{array}{l}-0.085 \\
(0.081)\end{array}$ & $\begin{array}{c}0.215 * * * \\
(0.044)\end{array}$ & $\begin{array}{c}-0.249 * * * \\
(0.057)\end{array}$ \\
\hline $\mathrm{NOF}_{\mathrm{t}-2}-\mathrm{NOF}^{*}{ }_{\mathrm{t}-1}$ & $\begin{array}{c}-0.052 * * * \\
(0.010)\end{array}$ & $\begin{array}{c}0.042 * * \\
(0.020)\end{array}$ & $\begin{array}{l}-0.010 \\
(0.010)\end{array}$ & $\begin{array}{c}0.012 \\
(0.014)\end{array}$ \\
\hline Replacement effect & $\begin{array}{c}0.729 * * \\
(0.288)\end{array}$ & & $\begin{array}{c}0.846 * * * \\
(0.126)\end{array}$ & \\
\hline Displacement effect & & $\begin{array}{c}0.906 * * * \\
(0.236)\end{array}$ & & $\begin{array}{c}1.182 * * * \\
(0.179)\end{array}$ \\
\hline $\mathrm{R}^{2}$ & 0.849 & 0.709 & 0.831 & 0.743 \\
\hline
\end{tabular}

Note: Results are from 3SLS regressions. Heteroskedasticity-consistent standard errors are between brackets. Both the entry and exit equations include industry fixed effects dummies (not reported). NOF* is computed from the estimated long term relation reported in Table 2. The undershooting sample includes those observations for which $\mathrm{NOF}_{\mathrm{t}-1}<$ NOF* $_{t-1}$. The overshooting sample includes those observations for which $\mathrm{NOF}_{\mathrm{t}-1}>\mathrm{NOF}_{\mathrm{t}-1}$. The variables UN, DUN, DF, SSP and FS are one period lagged only for the entry equation. The replacement (displacement) effect is computed by summing the coefficients for current and lagged exit (entry), and dividing this sum by one minus the coefficient for lagged entry (exit). Coefficients for lagged endogenous variables are in italics.

* significant at 0.10 level; ** significant at 0.05 level; *** significant at 0.01 level 


\subsection{Restoration of Equilibrium in Undershooting and Overshooting}

We now focus in more detail on the relative importance of both equilibrium-restoring mechanisms (i.e. replacement and displacement versus the effect of the variable $N O F_{t-2}-N O F_{t-1}^{*}$ ) using simulations -based on the estimated coefficients of Table 5- for under and overshooting. In particular, we assume a starting situation where the equilibrium number of firms in a market equals 100, and the absolute number of entries and exits both equal 10. In the first simulation, we assume that the actual number of firms initially equals 90 (undershooting) while in the second simulation we assume that the actual number of firms initially equals 110 (overshooting). ${ }^{12}$ For ease of exposition we also assume that the equilibrium number of firms does not change over time. In Tables 6 and 7 we show what happens to entry, exit, the number of firms and the extent of disequilibrium $\left(N O F_{t}-N O F_{t}^{*}\right)$ when we assume that the other variables in the model remain unchanged (in other words we make the usual ceteris paribus assumption), and only the replacement and displacement effects, and the effect of variable $\left(N O F_{t-2}-N O F^{*}{ }_{t-1}\right)$ influence the entry and exit levels, and the associated changes in the number of firms. For simplicity we also assume that the full cumulative replacement and displacement effects of an exogenous shock capitalize in one period of time. ${ }^{13}$

Several important observations can be drawn from these tables. ${ }^{14}$ First, for undershooting

\footnotetext{
${ }^{12}$ We use absolute numbers in this illustration as this is more insightful. It is also consistent with the coefficients reported in Table 5 . In our econometric model, both the entry and exit rate are scaled on the number of firms. In addition, the log difference between the actual and equilibrium number of firms approximately equals the absolute difference divided by the number of firms. So, basically all variables that play a role in equilibrium restoration are scaled on the number of firms. Therefore we may use the absolute numbers.

${ }^{13}$ This is a realistic assumption. Note that the coefficients of the contemporaneous entry and exit variables are much bigger than those of the lagged variables.

${ }^{14}$ The tables should be read as follows. In Table 6 , the starting situation is described in the first two rows ( $t=0$ and $t=1$ ). At the end of period 0 the number of firms equals 90 while entry and exit in period 1 both equal 10. By definition the number of firms at the end of period 1 then also equals 90 (using $N O F_{t}=N O F_{t-1}+E N T R Y Y_{t}-E X I T t_{t}$ ). In period 2 entry equals $0.729 \times$ Exit ${ }_{t-1}-0.052 \times\left(\right.$ NOF $_{t-2}-$ NOF $\left.*_{t-1}\right)=0.729 \times 10-0.052 \times-10=7.8$ (coefficients are taken from the left panel of Table 5). Analogously exit equals $0.906 \times$ Entry ${ }_{t-1}+0.042 \times\left(N O F_{t-2}-N O F *_{t-1}\right)=0.906 \times 10+0.042 \times-10=8.6$. At the end of period 2 this leads to a change in the number of firms of $-0.8(=7.8-8.6)$, hence the number of firms at the end of period 2 is 89.2. In the column "Contribution to error-correction" the net-entry effect is divided between a contribution of the entry and exit interrelation mechanism (i.e. the interaction of replacement and displacement effects) and a contribution of the extent of competition between incumbent firms (i.e. the effect of the variable $N O F_{t-2}-N O F *_{t-1}$ ). So, for instance, the entry/exit effect for period 2 equals $0.729 \times 10-0.906 \times 10=-1.8$. On the other hand, the isolated effect of NOF $t-2-N O F *_{t-1}$ equals $-0.052 \times-10-0.042 \times-10=0.9$. Hence, in period 2 the contribution of the entry/exit mechanism
} 
(Table 6), in accordance with hypothesis 3 , the process of convergence is slow and this is because the replacement and displacement interactions (column entry/exit) actually contribute to a divergence of the process away from equilibrium. This divergence effect is compensated by the incumbents mechanism (i.e. the effect of $N O F_{t-2}-N O F_{t-1}^{*}$ ), which does contribute to the restoration of equilibrium. In concreto, this mechanism leads to a 29.8 increase in the number of firms over the period considered, which compensates for the negative contribution to errorcorrection of -19.8 of the entry/exit mechanism. Second, for overshooting (Table 7) the process converges much faster: after six periods the number of firms already 'shoots' through its equilibrium value. Here the process converges much faster because both mechanisms work in the same direction: they both contribute to a decline of the number of firms (see the two columns under the header "Cumulative contribution" which display only negative values, at least until convergence is reached), and hence positively to the error-correction process, in this case. We also see that the contribution of the entry/exit mechanism is much stronger (-9.7) compared to that of the incumbent mechanism (-0.8). Third, combining the two observations above, we note that the equilibrium-restoring mechanisms are different for under and overshooting. Our estimation results imply that for undershooting, a lack of competition between incumbent firms contributes to restoration of equilibrium (creating room for new-firm entry) while in overshooting competition induced by new firms (in particular strong displacement) causes the number of firms to move towards equilibrium. Fourth, as an illustration, in Table 7 we also compute the effects when the process has already shot through its equilibrium, (erroneously) assuming that the coefficients estimated for overshooting also apply to situations of undershooting. We see that the number of firms keeps declining away from equilibrium. This illustrates that it is indeed necessary to distinguish between undershooting and overshooting situations when modelling the interrelation between entry and exit, because otherwise the process modelled shoots through its equilibrium and never returns (see the NOF column in Table 7) which is not realistic.

\footnotetext{
to the net-change in the number of firms is -1.8 , while the contribution of the incumbents mechanism is 0.9 (both rounded to one decimal). Note that the sum of these contributions exactly equals the difference between entry and exit (i.e. 7.8-8.6=$1.8+0.9=-0.8$ ). The final column contains the cumulative contributions of these two equilibrium restoring mechanisms. So, for instance for undershooting we see that after 119 periods the number of firms has increased with ten firms (i.e. from 90 to 100; the process has thus converged to equilibrium) and this increase can be split between the two mechanisms in -19.8 and 29.8 . Note that the entry/exit mechanism actually causes the number of firms to move away from equilibrium. Results in Table 7 are computed in a similar fashion, this time using the coefficients of the right panel of Table 5.
} 
Table 6: Equilibrium restoration in case of undershooting, simulation

\begin{tabular}{|c|c|c|c|c|c|c|c|c|c|}
\hline \multirow[b]{2}{*}{ Time } & \multirow[b]{2}{*}{ NOF* } & \multirow[b]{2}{*}{ NOF } & \multirow[b]{2}{*}{$\begin{array}{l}\text { NOF- } \\
\text { NOF* }^{*}\end{array}$} & \multirow[b]{2}{*}{ Entry } & \multirow[b]{2}{*}{ Exit } & \multicolumn{2}{|c|}{$\begin{array}{l}\text { Contribution to error- } \\
\text { correction }\end{array}$} & \multicolumn{2}{|c|}{$\begin{array}{l}\text { Cumulative } \\
\text { contribution }\end{array}$} \\
\hline & & & & & & Entry/exit & $\begin{array}{l}\text { Incum- } \\
\text { bents }\end{array}$ & Entry/exit & $\begin{array}{l}\text { Incum- } \\
\text { bents }\end{array}$ \\
\hline 0 & & 90.0 & & & & & & & \\
\hline 1 & 100 & 90.0 & -10.0 & 10.0 & 10.0 & & & & \\
\hline 2 & 100 & 89.2 & -10.8 & 7.8 & 8.6 & -1.8 & 0.9 & -1.8 & 0.9 \\
\hline 3 & 100 & 89.3 & -10.7 & 6.8 & 6.7 & -0.8 & 0.9 & -2.6 & 1.9 \\
\hline 4 & 100 & 89.0 & -11.0 & 5.4 & 5.7 & -1.3 & 1.0 & -3.9 & 2.9 \\
\hline 5 & 100 & 89.3 & -10.7 & 4.7 & 4.5 & -0.7 & 1.0 & -4.6 & 3.9 \\
\hline 6 & 100 & 89.3 & -10.7 & 3.8 & 3.8 & -1.0 & 1.0 & -5.6 & 5.0 \\
\hline 7 & 100 & 89.6 & -10.4 & 3.3 & 3.0 & -0.7 & 1.0 & -6.3 & 6.0 \\
\hline 8 & 100 & 89.8 & -10.2 & 2.8 & 2.6 & -0.8 & 1.0 & -7.2 & 7.0 \\
\hline 9 & 100 & 90.2 & -9.8 & 2.4 & 2.1 & -0.6 & 1.0 & -7.8 & 7.9 \\
\hline 10 & 100 & 90.4 & -9.6 & 2.0 & 1.8 & -0.7 & 1.0 & -8.5 & 8.9 \\
\hline 11 & 100 & 90.8 & -9.2 & 1.8 & 1.4 & -0.6 & 0.9 & -9.0 & 9.8 \\
\hline 12 & 100 & 91.1 & -8.9 & 1.5 & 1.2 & -0.6 & 0.9 & -9.6 & 10.7 \\
\hline 13 & 100 & 91.5 & -8.5 & 1.4 & 1.0 & -0.5 & 0.9 & -10.1 & 11.6 \\
\hline 14 & 100 & 91.8 & -8.2 & 1.2 & 0.9 & -0.5 & 0.8 & -10.6 & 12.4 \\
\hline 15 & 100 & 92.2 & -7.8 & 1.1 & 0.7 & -0.5 & 0.8 & -11.1 & 13.2 \\
\hline 16 & 100 & 92.5 & -7.5 & 1.0 & 0.6 & -0.4 & 0.8 & -11.5 & 14.0 \\
\hline 17 & 100 & 92.8 & -7.2 & 0.9 & 0.5 & -0.4 & 0.7 & -11.9 & 14.8 \\
\hline 18 & 100 & 93.1 & -6.9 & 0.8 & 0.5 & -0.4 & 0.7 & -12.3 & 15.5 \\
\hline 19 & 100 & 93.5 & -6.5 & 0.7 & 0.4 & -0.4 & 0.7 & -12.7 & 16.1 \\
\hline 20 & 100 & 93.7 & -6.3 & 0.7 & 0.4 & -0.4 & 0.6 & -13.1 & 16.8 \\
\hline 30 & 100 & 96.1 & -3.9 & 0.3 & 0.1 & -0.2 & 0.4 & -15.7 & 21.8 \\
\hline 31 & 100 & 96.3 & -3.7 & 0.3 & 0.1 & -0.2 & 0.4 & -15.9 & 22.2 \\
\hline 50 & 100 & 98.5 & -1.5 & 0.1 & 0.0 & -0.1 & 0.2 & -18.3 & 26.9 \\
\hline 51 & 100 & 98.6 & -1.4 & 0.1 & 0.0 & -0.1 & 0.1 & -18.4 & 27.0 \\
\hline 52 & 100 & 98.7 & -1.3 & 0.1 & 0.0 & -0.1 & 0.1 & -18.5 & 27.1 \\
\hline 118 & 100 & 99.9 & -0.1 & 0.0 & 0.0 & 0.0 & 0.0 & -19.8 & 29.8 \\
\hline 119 & 100 & 100.0 & 0.0 & 0.0 & 0.0 & 0.0 & 0.0 & -19.8 & 29.8 \\
\hline
\end{tabular}

Note: All variables in the table refer to absolute numbers. In the column "Contribution to error-correction" entry/exit refers to the replacement and displacement interactions while the column incumbents refers to the effect of the extent of disequilibrium in the number of (incumbent) firms. The bold-printed numbers in the last two columns at period 119 indicate the cumulative contribution of the two error-correction mechanisms at the time of convergence. 
Table 7: Equilibrium restoration in case of overshooting, simulation

\begin{tabular}{|c|c|c|c|c|c|c|c|c|c|}
\hline \multirow[b]{2}{*}{ Time } & \multirow[b]{2}{*}{$\mathrm{NOF}^{*}$} & \multirow[b]{2}{*}{ NOF } & \multirow[b]{2}{*}{$\begin{array}{l}\text { NOF- } \\
\text { NOF* }^{*}\end{array}$} & \multirow[b]{2}{*}{ Entry } & \multirow[b]{2}{*}{ Exit } & \multicolumn{2}{|c|}{$\begin{array}{l}\text { Contribution to error- } \\
\text { correction }\end{array}$} & \multicolumn{2}{|c|}{$\begin{array}{l}\text { Cumulative } \\
\text { contribution }\end{array}$} \\
\hline & & & & & & Entry/exit & $\begin{array}{l}\text { Incum- } \\
\text { bents }\end{array}$ & Entry/exit & $\begin{array}{l}\text { Incum- } \\
\text { bents }\end{array}$ \\
\hline 0 & & 110.0 & & & & & & & \\
\hline 1 & 100 & 110.0 & 10.0 & 10.0 & 10.0 & & & & \\
\hline 2 & 100 & 106.4 & 6.4 & 8.4 & 11.9 & -3.4 & -0.2 & -3.4 & -0.2 \\
\hline 3 & 100 & 106.4 & 6.4 & 10.0 & 10.0 & 0.2 & -0.2 & -3.1 & -0.4 \\
\hline 4 & 100 & 102.9 & 2.9 & 8.4 & 11.9 & -3.4 & -0.1 & -6.5 & -0.6 \\
\hline 5 & 100 & 102.9 & 2.9 & 10.0 & 10.0 & 0.1 & -0.1 & -6.4 & -0.7 \\
\hline 6 & 100 & 99.5 & -0.5 & 8.4 & 11.8 & -3.4 & -0.1 & -9.7 & -0.8 \\
\hline 7 & 100 & 99.5 & -0.5 & 10.0 & 10.0 & 0.1 & -0.1 & -9.7 & -0.8 \\
\hline 8 & 100 & 96.2 & -3.8 & 8.5 & 11.8 & -3.4 & 0.0 & -13.0 & -0.8 \\
\hline 9 & 100 & 96.2 & -3.8 & 10.0 & 10.0 & 0.0 & 0.0 & -13.0 & -0.8 \\
\hline 10 & 100 & 92.9 & -7.1 & 8.5 & 11.8 & -3.4 & 0.1 & -16.4 & -0.7 \\
\hline 25 & 100 & 71.8 & -28.2 & 10.0 & 10.0 & -0.6 & 0.5 & -42.5 & 4.3 \\
\hline 26 & 100 & 69.1 & -30.9 & 8.8 & 11.5 & -3.4 & 0.6 & -45.8 & 4.9 \\
\hline 55 & 100 & 35.9 & -64.1 & 10.1 & 10.2 & -1.4 & 1.3 & -108.1 & 34.0 \\
\hline 56 & 100 & 33.9 & -66.1 & 9.2 & 11.2 & -3.4 & 1.4 & -111.5 & 35.4 \\
\hline
\end{tabular}

Note: All variables in the table refer to absolute numbers. In the column "Contribution to error-correction" entry/exit refers to the replacement and displacement interactions while the column incumbents refers to the effect of the extent of disequilibrium in the number of (incumbent) firms. The bold-printed numbers in the last two columns at period 6 indicate the cumulative contribution of the two error-correction mechanisms at the time the number of firms 'shoots' through its equilibrium value.

The results provide some corroborating evidence for hypothesis 4 which can cause the adjustment process to differ between an overshoot and an undershoot. Therefore, the results are consistent with a scenario where barriers to exit and organizational inertia are relatively weaker constraints on exit than barriers to entry and start-up resource constraints are on entrants.

\section{Discussion and conclusions}

Despite the fact that the main contribution of the founders of entrepreneurship theory has been to provide an account of firm behaviour in disequilibrium, little empirical research on entrepreneurship has examined firm entry and exit in this context. In this paper, we redress this by investigating the interrelationship between firm entry and exit rates in disequilibrium. Our motivation is to generate a better understanding of the adjustment process in disequilibrium and 
indeed to highlight that disequilibrium itself gives rise to unique dynamics. To this end, we examine two mechanisms affecting the speed of adjustment towards equilibrium: first, the impact of the scale of markets over and under shooting carrying capacity on firm entry and exit activity, and second, the interrelationship between entry and exit. The former is accounted for by an investigation of the autonomous impact of the scale of disequilibrium (the gap between the actual and the equilibrium number of firms) on entry and exit levels. The latter is accounted for by an investigation of displacement (entry causing exit) and replacement (exit causing entry) effects. We estimate the contribution of each mechanism towards equilibrium restoration and also whether these relative contributions differ between market under and overshoot situations.

In order to assist our understanding and interpretation of entry and exit dynamics in disequilibrium, we also explore the properties of the economics of entrepreneurship and organizational ecology literatures enabling us to derive hypotheses of relevance for the likely dynamics of entry and exit in disequilibrium - including a view that the adjustment process may differ in under and overshoots.

Using a data base of Dutch retail industries over the period 1980-2001, we are able to distinguish between displacement (entry causing exit) and replacement (exit causing entry) effects. We introduce a new methodological approach which allows us to investigate whether the relations under consideration differ between situations of 'undershooting' (the actual number of firms is below the equilibrium number) and 'overshooting' (vice versa). We find that the equilibriumrestoring mechanisms are different in these two situations - being faster in over than undershoots. Our estimation results also imply that for undershooting, a lack of competition between incumbent firms contributes to restoration of equilibrium (creating room for new-firm entry) while in overshooting competition induced by new firms (in particular strong displacement) causes the number of firms to move towards equilibrium.

The results indicate that the main driver of equilibrium in an undershoot is that low market density attracts new entrants and enhances firm survival. In other words, a less crowded market offers more market opportunities and less competition for firms thereby providing a stimulus to entrepreneurship. It is interesting that in an overshoot the effects are not reversed so that high market density and competition don't bring about equilibrium by deterring entrepreneurs from entry. Instead, this high density market environment tends to give rise to weak/unfit firms who are 
perceived by entrants as 'easy targets' for displacement. In an overshoot entrepreneurs drive the market towards equilibrium by displacing incumbents at a much higher rate than they can do in an undershoot. Most prior discussion of an overshoot (see Day, 1997) emphasize that excessive competition between incumbents in an overshoot 'shakes' firms out of the market whereas our results show that in fact entrepreneurs are the drivers of equilibrium in an overshoot i.e. more of a new entrant driven 'displace-out' than an incumbent 'shakeout'. The results also provide some corroborating support for one implication of the economics and organizational ecology literatures, namely that we find the adjustment process to be faster in an overshoot than in an undershoot. This result is consistent with a scenario where barriers to exit and organizational inertia are relatively weaker constraints on exit than barriers to entry and start-up resource constraints are on entry.

We are aware of at least four limitations of our study. First, we do not distinguish between different types of firms. For instance, exiting behaviour may differ between recent and older entrants, or between firms run by entrepreneurs with different education levels. Our data set does not allow for such distinctions, but future research would benefit from data sets where different types of firms can be identified. Second, by estimating the long-run equilibrium number of firms as a single equation, we implicitly assume that under and overshoot situations occur at approximately the same frequency. Although this approach to estimating the equilibrium is quite common (see e.g. Burke, 1996, or Carree, 2002) and is a fundamental assumption for the use of OLS in applied industrial economics, it is fair to say that while having some intuitive appeal there is not a strong theoretical argument to justify this econometric property. Third, although the length of our time span (22 years) is reasonable, investigation of the long-run equilibrium and adjustment relations would be better facilitated if the time span was longer. Fourth, since we estimated our model for the retail industry generalization of the estimation results to other industries cannot be assumed but we believe that our empirical methodology should enable further empirical analysis to meet these ends.

Overall, we hope that this new evidence and methodology will both motivate and enable further research on the behaviour of entry and exit in disequilibrium. The results support the prejudices of the founders of entrepreneurship research, namely that disequilibrium is an enduring and dynamic business environment which affects the performance of businesses.

\section{References}

Amburgey, T.L., Kelly, D. and Barnett, W.P. (1993), Resetting the Clock: The Dynamics of 
Organizational Change and Failure, Administrative Science Quarterly, 38, 51-73.

Arrow, K.J. (1974), The Limits of Organization, New York: Norton.

Audretsch, D.B. and M. Fritsch (1994), On the Measurement of Entry Rates, Empirica 21, 105-113.

Barnett, W.P., and Carroll, G.R. (1995), Modelling Internal Organizational Change, Annual Review of Sociology, 21, 217-36.

Boone, C. and Van Witteloostuijn, A. (1995), Industrial Organization and Organizational Ecology: The Potential for Cross-Fertilization, Organizational Studies, 16, 265-298.

Burke, A.E. (1996), Economic Integration and New Firm Formation: Britain's Impact on Irish Enterprise, Review of Industrial Organization 11, 183-200.

Burke, A., FitzRoy, F. and Nolan, M. (2000), When Less is more: Distinguishing Between Entrepreneurial Choice and Performance, Oxford Bulletin of Economic and Statistics, 62(5), 565-587.

Burke, A.E., Van Stel, A., and Thurik, A.R. (2010), Blue Ocean v. Five Forces, Harvard Business Review, May 2010.

Carree, M.A. (2002), Does Unemployment Affect the Number of Establishments? A Regional Analysis for US States, Regional Studies 36(4), 389-398.

Carree, M.A., and Thurik, A.R. (1996), Entry and Exit in Retailing: Incentives, Barriers, Displacement and Replacement, Review of Industrial Organization 11, 155-172.

Carroll, G. (1985), Concentration and Specialization: Dynamics of Niche Width in Populations of Organizations, American Journal of Sociology, 90, 1262-83.

Casson, M. (1982), The Entrepreneur: An Economic Theory, Oxford, UK: Martin Robertson.

Chamberlin, E.H. (1933), The Theory of Monopolistic Competition, Harvard University Press, Cambridge MA.

Day, G.S. (1997), Strategies for Surviving a Shakeout, Harvard Business Review, 75(2), 92-102.

Dean, T.J. and Meyer, G.D. (1999), Industry Environments and New Venture Formations in US Manufacturing: A Conceptual and Empirical Analysis of Demand Determinants, Journal of Business Venturing, 11(2), 107-132.

Delacroix, J. and Carroll, G.R. (1983), Organizational foundings: an ecological study of the newspaper industries of Argentina and Ireland, Administrative Science Quarterly, 28, 274-291.

Dobrev, S., and Barnett, W. (2001), Organizational Roles and Transitions in Entrepreneurship, Working paper, University of Chicago, Graduate School of Business.

Dobrev, S., Kim, T-Y, and Hannan, M.T. (2001), Dynamics of niche width and resource partitioning, American Journal of Sociology, 106(5), 1299-1337.

Evans, D. and Jovanovic, B. (1989), An Estimated Model of Entrepreneurial Choice under Liquidity Constraints, Journal of Political Economy, 97(4), 519-535.

Geroski, P.A. (2001). Exploring the Niche Overlaps Between Organizational Ecology and Industrial Economics, Industrial and Corporate Change, 10(2), 507-540.

Hannan, M.T. and Freeman, J. (1977), The population ecology of organizations, American Journal of Sociology, 60, 539-544.

Hannan, M.T. and Freeman, J. (1984), Structural Inertia and Organizational Change, American 
Sociological Review, 49, 149-64.

Hannan, M.T. and Freeman, J. (1989), Organizational Ecology, Cambridge, MA, Harvard University Press.

Hannan, MT. and Carroll, G. R. (1992), Dynamics of Organizational Populations: Density, Legitimation, and Competition. New York: Oxford University Press.

Hawley, A. (1968), Human Ecology. In the 'International Encyclopedia of the Social Sciences' edited by David Sills, New York: Macmillan.

Heij, C., P. de Boer, Ph.H. Franses, T. Kloek and H.K. van Dijk (2004), Econometric Methods with Applications in Business and Economics, Oxford: Oxford University Press.

Hotelling, HH. (1929). Stability in Competition, The Economic Journal, 39, 41-57.

Knight, F.H. (1921), Risk, Uncertainty and Profit, Boston, MA: Houghton Mifflin.

Martin, S. (2002), Advanced Industrial Economics (2 ${ }^{\text {nd }}$ Edition), Oxford, UK, Blackwell Publishing.

Minniti, M. and Levesque, M. (2008), Recent Developments in the Economics of Entrepreneurship, Journal of Business Venturing, 23(6), 603-612.

Nelson, R., Winter, S. (1982), An Evolutionary Theory of Economic Change, Cambridge, MA, Harvard University Press.

Parker, D. and Stead, R. (1991), Profit and Enterprise: The Political Economy of Profit, New York: Harvester Wheatsheaf.

Parker, S.C. (2004), The Economics of Self-employment and Entrepreneurship, Cambridge, UK: Cambridge University Press.

Peli, G. (1997), The Niche Hikers Guide to Population Ecology: A Reconstruction of Niche Theory Using Logic. In Sociological Methodology by A. E. Raftery (ed). Cambridge, UK: Blackwell.

Schultz, T.W. (1975), The Value of the Ability to Deal with Disequilibria, Journal of Economic Literature, 13(3), 827-846.

Schultz, T.W. (1980), Investment in Entrepreneurial Ability, Scandinavian Journal of Economics 82(4), 437-448.

Schumpeter, J.A. (1934), The Theory of Economic Development, Cambridge, MA: Harvard University Press.

Shane, S. (2003), A General Theory of Entrepreneurship: The Individual-Opportunity Nexus, Cheltenham, UK: Edward Elgar.

Stinchcombe, A.L. (1965), Social Structure and Organizations. In 'Handbook of Organizations' edited by James G. March, Chicago: Rand McNally.

Sutton, J. (1991), Sunk costs and Market Structure: Price Competition, Advertising and the Evolution of Concentration, Cambridge, MA, MIT Press.

Thurik, A.R., M. Carree, A. van Stel and D.B. Audretsch (2008), Does Self-employment Reduce Unemployment?, Journal of Business Venturing 23(6), 673-686.

Tirole, J. (1988), The Theory of Industrial Organization, Cambridge MA: The MIT Press.

Von Mises, L. (1949), Human Action: A Treatise on Economics, London: Hodge. 


\section{Appendix 1: Developing the estimation model}

The aim of our paper is to investigate whether excessive or deficient numbers of incumbent firms (i.e. the extent of disequilibrium) in itself form the main equilibrating mechanism, or, alternatively, the interrelation between entry and exit (i.e. replacement and displacement effects). We also ask ourselves the question whether the relative importance of these two mechanisms differs between undershoot and overshoot situations.

In this appendix we develop an empirical model describing the interrelation between entry, exit and the number of firms in an industry, which allows us to address these issues. To provide context we initially outline some of the approaches used in the literature to account for the influence of some of the elements of disequilibrium on entry and exit. It is important to point out that while our model draws inspiration from earlier models in the sequence below, it is not derived from them as it is created to account for influences not considered in the earlier models.

\section{First approach: modelling interrelations between entry and exit}

In this approach it is assumed that the number of firms $N O F_{t}$ in an industry is a function of factors $X_{t}=\left\{x_{i=1 t}, \ldots, x_{n t}\right\}$ affecting the capacity of an industry to support viable firms. Therefore, the elements of vector $X_{t}$ include elements relating to firm viability such as factors relating to the revenues and costs of firms, demand, entry/exit barriers, industry consumer spending and liquidity. $N O F_{t}=N O F_{t}\left(X_{t}\right)$

Substituting equation (1) into the identity $N O F_{t}-N O F_{t-1}=E N T R Y_{t}-E X I T_{t}$ (assuming the number of firms is measured at the end of year t $)$ or $E N T R Y_{t}=E X I T_{t}+\left(N O F_{t}-N O F_{t-1}\right)$ provides the theoretical basis for estimating entry and exit equations in the following specific form.

$$
\begin{aligned}
& \operatorname{ENTRY}_{t}=\alpha_{0}+\alpha_{1} \operatorname{EXIT}_{t}+\sum_{i=1}^{n} \alpha_{i}^{\prime}\left(x_{i t}-x_{i t-1}\right) \\
& \operatorname{EXIT}_{t}=\beta_{0}+\beta_{1} \operatorname{ENTRY}_{t}+\sum_{i=1}^{n} \beta_{i}^{\prime}\left(x_{i t}-x_{i t-1}\right)
\end{aligned}
$$

Carree and Thurik (1996) estimate entry and exit equations which are an adjustment of this basic form in order to account for equilibrating effects; particularly replacement and displacement relationships between entry and exit. Augmenting equations (2) and (3) to account for lagged entry 
and exit gives rise to equations (4) and (5). ${ }^{15}$ In equation (4) the long-run replacement effect can be computed as the sum of the coefficients belonging to the exit variables, corrected for the impact of the lagged entry rate. Hence, the replacement effect can be computed as $\frac{\alpha_{1}+\alpha_{2}}{1-\alpha_{3}}$. Analogously, from equation (5) the long-run displacement effect can be computed as $\frac{\beta_{1}+\beta_{3}}{1-\beta_{2}}$.

$$
\begin{aligned}
& \operatorname{ENTRY}_{t}=\alpha_{0}+\alpha_{1} \operatorname{EXIT}_{t}+\alpha_{2} \operatorname{EXIT}_{t-1}+\alpha_{3} \operatorname{ENTRY}_{t-1}+\sum_{i=1}^{n} \alpha_{i}^{\prime}\left(x_{i t}-x_{i t-1}\right) \\
& \operatorname{EXIT}_{t}=\beta_{0}+\beta_{1} \text { ENTRY }_{t}+\beta_{2} \operatorname{EXIT}_{t-1}+\beta_{3} \text { ENTRY }_{t-1}+\sum_{i=1}^{n} \beta_{i}^{\prime}\left(x_{i t}-x_{i t-1}\right)
\end{aligned}
$$

This type of model has a number of properties which from an empirical perspective are quite restrictive as they impose questionable features on the equilibrium process. Firstly, either displacement dominates replacement or vice versa implying that the long term adjustment process tends to either a zero or infinite number of firms respectively. Secondly, since replacement and displacement effects are constant they cannot vary depending on whether there are too many (relative to a sustainable number implied from equation 1) or too few firms in the market. In other words, these effects are unaffected by the intensity of competition in the market. Thirdly, the model is not affected by the extent to which the actual number of firms deviates from the sustainable number so that it makes no difference whether there are 5\% too few firms, $5 \%$ too many or indeed $500 \%$ too many firms relative to the sustainable number.

\section{Second approach: specifying an augmented error correction model}

An alternative approach adopted by Burke (1996) involves using a formal econometric error correction mechanism (ECM). This requires explicit interpretation of a long-run sustainable or equilibrium number of firms $N O F_{t} *$ from equation (1) where $\operatorname{NOF}_{t} *=\operatorname{NOF}_{t} *\left(X_{t}\right)$. Hence, instead of assuming that the actual number of firms $\left(N O F_{t}\right)$ is a function of $X_{t}$ (as in the first approach), it is now assumed that the equilibrium number of firms $\left(N O F_{t}^{*}\right)$ is a function of $X_{t}$. The existence of an equilibrating process is then tested through an error-correction model represented in equation (6) where the existence of an equilibrating process depends on the parameter $z$ being

\footnotetext{
${ }^{15}$ Please note that equations (4) and (5) are not equivalent to equations (2) and (3). Instead, equations (4) and (5) are extended, more flexible versions of equations (2) and (3), allowing for path dependency in the entry and exit rates.
} 
negative and significant.

$$
N O F_{t}-N O F_{t-1}=\omega_{0}+\sum_{i=1}^{n} \omega_{i}\left(w_{i t}-w_{i t-1}\right)+z\left[N O F_{t-1}-N O F^{*}{ }_{t-1}\right]
$$

Letting $\lambda=1$ and again making use of $N O F_{t}-N O F_{t-1}=E N T R Y_{t}-E X I T_{t}$ allows us to define entry and exit equations. ${ }^{16}$

$$
\begin{aligned}
& \operatorname{ENTRY}_{t}=\omega_{0}+\sum_{i=1}^{n} \omega_{i}\left(w_{i t}-w_{i t-1}\right)+z\left[N O F_{t-1}-N O F^{*}{ }_{t-1}\right]+\lambda E X I T_{t} \\
& \operatorname{EXIT~}_{t}=-\omega_{0}-\sum_{i=1}^{n} \omega_{i}\left(w_{i t}-w_{i t-1}\right)-z\left[N O F_{t-1}-N O F^{*}{ }_{t-1}\right]+\lambda E N T R Y_{t}
\end{aligned}
$$

By definition $N O F_{t}=N O F_{t-1}+E N T R Y_{t}-E X I T_{t}$ so by substitution $N O F_{t-1}-N O F_{t-1}^{*}$ can be rewritten as: $\quad N O F_{t-1}-N O F_{t-1}^{*}=N O F_{t-2}+E N T R Y_{t-1}-E X I T_{t-1}-N O F_{t-1}^{*}$. This means that equations (7) and (8) can be rewritten to reveal displacement and replacement effects as follows:

$$
\begin{aligned}
& \operatorname{ENTRY}_{t}=\omega_{0}+\sum_{i=1}^{n} \omega_{i}\left(w_{i t}-w_{i t-1}\right)+z \operatorname{ENTRY}_{t-1}-z \operatorname{EXIT}_{t-1}+z\left[N O F_{t-2}-N O F^{*}{ }_{t-1}\right]+\lambda \operatorname{EXIT}_{t}(7 a) \\
& \operatorname{EXIT}_{t}=-\omega_{0}-\sum_{i=1}^{n} \omega_{i}\left(w_{i t}-w_{i t-1}\right)-z \operatorname{ENTRY}_{t-1}+z \operatorname{EXIT}_{t-1}-z\left[N O F_{t-2}-\operatorname{NOF}_{t-1}{ }_{t-1}\right]+\lambda \operatorname{ENTRY}_{t}(8 a)
\end{aligned}
$$

Equations (7a) and (8a) illustrate the strength of the formal error correction approach in that it can be decomposed into effects attributable to incumbent firms (variable $\left(N O F_{t-2}-N O F^{*}{ }_{t-1}\right)$ ) and new and exiting firms (the entry and exit variables on the right hand side of the equations). Therefore, estimation of equations (7a) and (8a) is more comprehensive than Carree and Thurik's (1996) specification as it accounts for displacement and replacement effects but unlike their model it also accounts for a disequilibrium in the number of incumbent firms. The new unearthed ECM term $z\left[N O F_{t-2}-N O F_{t-1}^{*}\right]$ in equations (7a) and (8a) is intuitive as it gives a measure to the deviation from the actual number at the start of the previous year from the sustainable number over the year. Thus, it provides a good gauge of whether competition and hence profit opportunities are currently above or below a sustainable level - the exact sort of information one would expect to influence entry and exit decisions.

\footnotetext{
${ }^{16}$ The newly introduced parameter $\lambda$ is necessarily equal to one in equations (7) and (8) but will be relaxed later on in equations (9)
} 
However, the weakness of the ECM approach is that the specification of equations (7a) and (8a) imply that a fixed parameter $z$ applies to entry, exit and disequilibrium in the number of incumbent firms. ${ }^{17}$ Unless one imagines an extreme and unrealistic scenario where firms are entirely homogeneous, there is little in economic theory to justify such a restriction.

Therefore, a more theoretically and empirically robust approach is to estimate equations (7a) and (8a) directly where the parameter values on (current and lagged) ENTRY and EXIT and deviations of the actual number of incumbents from the equilibrium number are freely estimated rather than constrained to be uniform. This gives rise to the following entry and exit disequilibrium adjustment equations. The main novel contribution of this approach is that it identifies the unique roles played by new and incumbent firms in the disequilibrium adjustment process.

$$
\begin{aligned}
& \text { ENTRY }_{t}=\alpha_{0}+\sum_{i=1}^{n} \alpha_{i}\left(w_{i t}-w_{i t-1}\right)+\psi\left(N O F_{t-2}-N O F_{t-1}^{*}\right)+\varphi \operatorname{ENTRY~}_{t-1}+\gamma \operatorname{EXIT}_{t-1}+\mu \operatorname{EXIT}_{t} \\
& \operatorname{EXIT}_{t}=\beta_{0}+\sum_{i=1}^{n} \beta_{i}\left(w_{i t}-w_{i t-1}\right)+\theta\left(N O F_{t-2}-N O F_{t-1}^{*}\right)+\rho \operatorname{ENTRY}_{t-1}+\tau \operatorname{EXIT}_{t-1}+\phi \operatorname{ENTRY}_{t}
\end{aligned}
$$

\section{Distinguishing between different types of disequilibrium}

This then leaves us with the remaining problem we noted earlier in that such an estimation implies that the coefficients on the replacement and displacement effects are uniform in both under and overshoots. However, we postulate that the adjustment process may not be symmetric when comparing market overshoots $N O F_{t}>N O F{ }_{t}$ and undershoots $N O F_{t}<N O F{ }_{t}$. Competition is excessive in an overshoot to the point that the number of firms must decline. In such circumstances one would expect a considerable body of vulnerable weak firms i.e. less fit (Hannan and Freeman, 1989 ) in terms of their ability to generate sufficient profits to survive and re-invest for the future. Correspondingly, in an undershoot more profit opportunities exist and incumbent firms are able to earn temporary monopolistic profits where even weak firms find it easier to be sustainable (Tirole, 1988). So one might reasonably expect the displacement effect (entry causing exit) to be weaker in an undershoot compared to an overshoot. Correspondingly, one would expect the replacement effect (exit causing entry, Delacroix and Carroll, 1983) to be stronger in an undershoot where there

and (10).

${ }^{17}$ As derived above equations (7a) and (8a) also imply that displacement and replacement effects are identical; if $\lambda=1$ then both the replacement and the displacement effect equal $(\lambda-z) /(1-z)=(1-z) /(1-z)=1$. This is not realistic. 
is less tight niche packing (Hannan and Freeman, 1989 and Hannan and Carroll, 1992) and more market opportunities. Hence, in these circumstances, the adjustment process is not symmetric.

Therefore, we propose an approach which involves splitting the data set into over and undershoots and then estimate the new entry and exit equations as follows (where superscripts $u$ and $o$ indicate undershoot and overshoot sample equations respectively). For brevity we only report the undershoot equations.

$$
\begin{aligned}
& \operatorname{ENTRY}_{t}^{u}=\alpha_{0}^{u}+\sum_{i=1}^{n} \alpha_{i}^{u}\left(w_{i t}-w_{i t-1}\right)+\psi^{u}\left(N O F_{t-2}-N O F^{*}{ }_{t-1}\right)+\varphi^{u} \operatorname{ENTRY~}_{t-1}+\gamma^{u} \operatorname{EXIT~}_{t-1}+\mu^{u} \operatorname{EXIT}_{t} \\
& \operatorname{EXIT}_{t}^{u}=\beta_{0}^{u}+\sum_{i=1}^{n} \beta_{i}^{u}\left(w_{i t}-w_{i t-1}\right)+\theta^{u}\left(N O F_{t-2}-N O F_{t-1}^{*}\right)+\rho^{u} \operatorname{ENTRY~}_{t-1}+\tau^{u} \operatorname{EXIT}_{t-1}+\phi^{u} \operatorname{ENTRY~}_{t}
\end{aligned}
$$

We can now write the replacement $(R)$ and displacement $(D)$ effects for under (u) and overshoots (o) as:

$$
R^{u}=\frac{\gamma^{u}+\mu^{u}}{1-\varphi^{u}} ; \quad R^{o}=\frac{\gamma^{o}+\mu^{o}}{1-\varphi^{o}} ; \quad D^{u}=\frac{\rho^{u}+\phi^{u}}{1-\tau^{u}} ; \quad D^{o}=\frac{\rho^{o}+\phi^{o}}{1-\tau^{o}}
$$

In addition, the role of the scale of disequilibrium in the number of incumbent firms in restoring equilibrium is reflected by parameters $\psi^{u}$ and $\theta^{u}$ (undershooting) and $\psi^{o}$ and $\theta^{o}$ (overshooting). Together with the replacement and displacement effects from equation (11) these parameters determine the course of the error-correction process.

In our empirical model specification (see Section 3.2) we scale the numbers of entries and exits as well as the difference between the actual and equilibrium number of firms, in order to correct for market size differences between shop types. We make the variables comparable across shop types by expressing entry and exit as a percentage of the number of firms (Audretsch and Fritsch, 1994) and by expressing the gap between the actual and equilibrium number of firms as a log-difference (basically expressing the gap as a percentage of the stock of firms). 


\section{Appendix 2: Results for balanced panel}

Table 8 presents the results for the full model when using a balanced data set, i.e., when the shop types for which less observations (years) are available, are removed from the data sample. In concreto, the shop types that are removed for this exercise are the 13 shop types for which the number of observations is smaller than 22 (i.e., those for which $\mathrm{N}<22$ in Table 1). When comparing Tables 5 and 8, we conclude that results are qualitatively the same. Hence, the results are robust for excluding the shop types for which the period of data availability is relatively short. 
Table 8: Estimation results, under and overshooting, including error-correction mechanism for incumbent firms

\begin{tabular}{|c|c|c|c|c|}
\hline & \multicolumn{2}{|c|}{ Undershooting $(\mathrm{N}=245)$} & \multicolumn{2}{|c|}{ Overshooting $(\mathrm{N}=203)$} \\
\hline & ENTRY & EXIT & ENTRY & EXIT \\
\hline $\mathrm{PMI}_{\mathrm{t}-1}$ & $\begin{array}{c}0.014 * * * \\
(0.004)\end{array}$ & $\begin{array}{c}-0.018 * * * \\
(0.005)\end{array}$ & $\begin{array}{c}0.010 * * * \\
(0.004)\end{array}$ & $\begin{array}{c}-0.010 * * * \\
(0.004)\end{array}$ \\
\hline $\mathrm{DCS}_{\mathrm{t}-1}$ & $\begin{array}{c}0.00003 \\
(0.013)\end{array}$ & $\begin{array}{c}-0.003 \\
(0.011)\end{array}$ & $\begin{array}{c}-0.005 \\
(0.011)\end{array}$ & $\begin{array}{c}0.006 \\
(0.011)\end{array}$ \\
\hline $\mathrm{UN}_{(\mathrm{t}-1)}$ & $\begin{array}{c}-0.113 * * * \\
(0.017)\end{array}$ & $\begin{array}{c}0.059 * * \\
(0.029)\end{array}$ & $\begin{array}{l}-0.022 \\
(0.014)\end{array}$ & $\begin{array}{c}0.017 \\
(0.016)\end{array}$ \\
\hline $\operatorname{DUN}_{(\mathrm{t}-1)}$ & $\begin{array}{c}0.056 * * * \\
(0.020)\end{array}$ & $\begin{array}{c}-0.136 * * * \\
(0.048)\end{array}$ & $\begin{array}{c}0.007 \\
(0.011)\end{array}$ & $\begin{array}{l}-0.026 \\
(0.016)\end{array}$ \\
\hline $\mathrm{DF}_{(\mathrm{t}-1)}$ & $\begin{array}{c}-0.012 \\
(0.027)\end{array}$ & $\begin{array}{c}0.003 \\
(0.040)\end{array}$ & $\begin{array}{l}-0.005 \\
(0.017)\end{array}$ & $\begin{array}{c}0.007 \\
(0.018)\end{array}$ \\
\hline $\operatorname{SSP}_{(\mathrm{t}-1)}$ & $\begin{array}{l}-0.020 \\
(0.029)\end{array}$ & $\begin{array}{l}-0.003 \\
(0.027)\end{array}$ & $\begin{array}{l}-0.021 \\
(0.015)\end{array}$ & $\begin{array}{c}0.024 \\
(0.020)\end{array}$ \\
\hline $\mathrm{FS}_{(\mathrm{t}-1)}$ & $\begin{array}{c}0.210 \\
(0.418)\end{array}$ & $\begin{array}{l}-0.027 \\
(0.303)\end{array}$ & $\begin{array}{c}0.182 \\
(0.208)\end{array}$ & $\begin{array}{l}-0.132 \\
(0.244)\end{array}$ \\
\hline IR & $\begin{array}{c}-0.567 * * * \\
(0.141)\end{array}$ & $\begin{array}{c}0.519 * * * \\
(0.139)\end{array}$ & $\begin{array}{c}-0.292 * * \\
(0.121)\end{array}$ & $\begin{array}{c}0.299 * * \\
(0.124)\end{array}$ \\
\hline HP & $\begin{array}{c}-0.00038 * * * \\
(0.00007)\end{array}$ & $\begin{array}{c}0.00034 * * * \\
(0.00009)\end{array}$ & $\begin{array}{c}-0.00022 * * * \\
(0.00005)\end{array}$ & $\begin{array}{c}0.00022 * * * \\
(0.00005)\end{array}$ \\
\hline EXIT & $\begin{array}{c}0.687 * * * \\
(0.266)\end{array}$ & & $\begin{array}{c}0.920 * * * \\
(0.130)\end{array}$ & \\
\hline ENTRY & & $\begin{array}{c}0.915 * * * \\
(0.324)\end{array}$ & & $\begin{array}{c}1.065 * * * \\
(0.145)\end{array}$ \\
\hline $\mathrm{EXIT}_{\mathrm{t}-1}$ & $\begin{array}{c}-0.186 * * \\
(0.082)\end{array}$ & $\begin{array}{c}0.171 * * \\
(0.079)\end{array}$ & $\begin{array}{c}-0.225 * * * \\
(0.064)\end{array}$ & $\begin{array}{c}0.242 * * * \\
(0.067)\end{array}$ \\
\hline ENTRY $_{\mathrm{t}-1}$ & $\begin{array}{c}0.235 * * * \\
(0.079)\end{array}$ & $\begin{array}{l}-0.145 \\
(0.128)\end{array}$ & $\begin{array}{c}0.200 * * * \\
(0.055)\end{array}$ & $\begin{array}{c}-0.206 * * * \\
(0.059)\end{array}$ \\
\hline $\mathrm{NOF}_{\mathrm{t}-2}-\mathrm{NOF}_{\mathrm{t}-1}$ & $\begin{array}{c}-0.051 * * * \\
(0.009)\end{array}$ & $\begin{array}{c}0.042 * * \\
(0.021)\end{array}$ & $\begin{array}{l}-0.012 \\
(0.012)\end{array}$ & $\begin{array}{c}0.012 \\
(0.014)\end{array}$ \\
\hline Replacement effect & $\begin{array}{c}0.654 * * \\
(0.303)\end{array}$ & & $\begin{array}{c}0.868 * * * \\
(0.155)\end{array}$ & \\
\hline Displacement effect & & $\begin{array}{c}0.930 * * * \\
(0.303)\end{array}$ & & $\begin{array}{c}1.134 * * * \\
(0.187)\end{array}$ \\
\hline $\mathrm{R}^{2}$ & 0.810 & 0.686 & 0.809 & 0.756 \\
\hline
\end{tabular}

Note: Results are from 3SLS regressions. Heteroskedasticity-consistent standard errors are between brackets. Both the entry and exit equations include industry fixed effects dummies (not reported). NOF* is computed from the estimated long term relation reported in Table 2. The undershooting sample includes those observations for which $\mathrm{NOF}_{\mathrm{t}-1}<$ NOF* $_{t-1}$. The overshooting sample includes those observations for which $\mathrm{NOF}_{\mathrm{t}-1}>\mathrm{NOF}_{\mathrm{t}-1}$. The variables UN, DUN, DF, SSP and FS are one period lagged only for the entry equation. The replacement (displacement) effect is computed by summing the coefficients for current and lagged exit (entry), and dividing this sum by one minus the coefficient for lagged entry (exit). Coefficients for lagged endogenous variables are in italics.

* significant at 0.10 level; ** significant at 0.05 level; *** significant at 0.01 level 